\title{
O conhecimento pedagógico do conteúdo referente ao tema Natureza da Ciência na formação inicial de professores de Física ${ }^{+*}$
}

\author{
Boniek Venceslau da Cruz Silva ${ }^{1}$ \\ Universidade Federal do Piauí \\ Teresina - PI \\ André Ferrer P. Martins ${ }^{1}$ \\ Universidade Federal do Rio Grande do Norte \\ Natal - RN
}

\section{Resumo}

O conhecimento pedagógico do conteúdo (PCK, do inglês Pedagogical Content Knowledge) é um conhecimento desenvolvido ao longo da formação docente e no exercício de sua profissão, caracterizando-se como um conhecimento próprio do professor. Entendemos que o PCK pode ser uma ferramenta útil para a compreensão do como os professores desenvolvem estratégias didáticas para a discussão de aspectos da Natureza da Ciência (NdC) em sala de aula. Na nossa pesquisa, de natureza qualitativa, buscamos investigar como 9 (nove) futuros professores de Física e estudantes de uma universidade pública brasileira mobilizam seus PCK para o ensino de aspectos da Natureza da Ciência (PCK/NdC). Devido à natureza tácita do PCK, utilizamos várias formas de coleta de dados, como, por exemplo, questionários, entrevistas e diários de reflexão do participante. Os resultados obtidos nos permitiram perceber alguns elementos que facilitaram ou dificultaram a mobilização do PCK/NdC do grupo investigado. Por exemplo, a complexidade e o ineditismo destas temáticas nos cursos de formação de professores de Física apresentou-se como um fator que dificultou a produção de estratégias didáticas para o ensino de aspectos da NdC, causando receios nos futuros professores, principalmente, no que diz respeito às suas próprias imagens diante dos estudantes da Educação Básica ao receberem essas novas pro-

\footnotetext{
${ }^{+}$Pedagogical content knowledge about the Nature of Science in the Undergraduate Physics Education Course

* Recebido: maio de 2019. Aceito: outubro de 2019.

${ }^{1}$ E-mails: boniek@ufpi.edu.br; andre.ferrer@pq.cnpq.br
} 
postas. Atrelado a isso, o pouco conhecimento do contexto, ou seja, o lócus de trabalho dos professores, pois o grupo investigado não apresentava experiências didáticas na sala de aula, propriamente dita, dificultou a estruturação de conhecimentos de estratégias didáticas para o ensino de aspectos da NdC e, consequentemente, do PCK/NdC. A partir das análises realizadas, embora os licenciandos investigados ainda estejam na fase de amadurecimento dos seus PCK/NdC, sugerimos que os cursos de formação inicial direcionem outro olhar para a questão de como os licenciandos mobilizam os conhecimentos necessários para o ensino de conteúdos metacientíficos e, por consequência, seus PCK/NdC. Uma saída, emergente da nossa investigação, seria a inserção de mais práticas cooperativas e reflexivas na formação destes professores.

Palavras-chave: Conhecimento Pedagógico do Conteúdo; Natureza da Ciência; Formação de Professores de Física.

\begin{abstract}
The Pedagogical Content Knowledge (PCK) is a knowledge developed during the teacher training phase and the practice of the profession, characterizing itself as an own knowledge of the teacher. We understand that PCK can be a useful tool for understanding how teachers develop didactic strategies for discussing aspects of the Nature of Science (NOS) in the classroom. In our qualitative research, we investigate how 9 (nine) future physics teachers, students of a Brazilian public university mobilize their PCK for teaching aspects of the Nature of Science (PCK/NOS). Due to the tacit nature of the PCK, we used various forms of data collection, such as questionnaires, interviews and reflection diaries of the participant. The results show some elements that facilitated or made difficult the mobilization of PCK/NOS of the investigated group. For example, the complexity and the novelty of these themes in the training courses of physics teachers was a factor that made it difficult to produce didactic strategies for the teaching of NOS aspects, causing fears in future teachers, especially in refers to their own images before the students of basic education when they receive these new proposals. Linked to this, the lack of knowledge of the context, that is, the working locus of the teachers, since the group investigated did not present didactic experiences in the classroom itself, made it difficult to mobilize knowledge of didactic strategies for teaching aspects of NOS and the PCK/NOS. Based on the analyzes in this research, although the future teachers investigated are still
\end{abstract}


in the phase of maturation of their PCK/NOS, we suggest that the initial training courses investigate how teachers in training mobilize the knowledge necessary for the teaching of metascientific contents and, consequently, their PCK/NOS. One suggestion, emerging from our research, would be the insertion of more cooperative and reflexive practices in the training of these teachers.

Keywords: Pedagogical Content Knowledge; Nature of Science; Physics Teacher Training.

\section{Introdução}

O professor é um profissional que, ao exercer a sua função, ou quando está aprendendo sobre ela, mobiliza diferentes conhecimentos, valores e impressões sobre o que ensina, como ensina, a quem ensina, as finalidades de ensinar determinado tema, dentre outras. $\mathrm{Ou}$ seja, na base de ensino ${ }^{2}$ do professor estão inseridas atividades relacionadas a como organizar uma estratégia didática, avaliar a aprendizagem dos estudantes ou ao suporte teórico e metodológico para o ensino de um determinado tópico, por exemplo.

Embora, como apontado acima, exista um leque de domínios que fazem parte da base de ensino do professor, neste trabalho destacamos o conhecimento pedagógico do conteúdo 3 como o conhecimento que o professor possui acerca de como lecionar um determinado tema para seus estudantes, no nosso caso, conteúdos metacientíficos ${ }^{4}$.

A definição de PCK surge, inicialmente, nos trabalhos de Shulman (1986; 1987), que o define como o amálgama entre o conteúdo e a pedagogia. Devido à importância que o PCK assumiu, principalmente a partir da década de noventa do século passado, surgiram várias investigações sobre o PCK em inúmeras revistas que abordam temas relacionados ao campo da Didática das Ciências, com destaque aos trabalhos de revisão de literatura de Abel (2008), Kind (2009), Fernandez (2015) e Verdugo-Perona; Solaz-Portolés e José-Lopez (2017), como também livros que se debruçam a esmiuçar esse conceito (ver, por exemplo: Gess-Newsome e Lederman (1999); Marcon (2013) e Berry; Friedrichsen, Loughran (2015)).

A nossa compreensão de PCK vai ao encontro das primeiras ideias de Shulman, o qual define o PCK como a transformação de conhecimentos da base de ensino. Embora o pesquisador, na sua definição clássica do PCK como o amálgama entre o conteúdo e a pedagogia,

\footnotetext{
2 O termo "base de ensino" é uma tradução de knowledge base, cunhado por Shulman (1986). Para o investigador, os professores em formação ou em exercício possuem um leque de conhecimentos necessários para o exercício de sua profissão. Tal leque de conhecimentos, Shulman intitulou de knowledge base.

3 No contexto ibero-americano, o PCK também recebe o nome de conhecimento didático do conteúdo (por exemplo: Bolívar (2005) e Acevedo (2009)).

${ }^{4}$ Neste trabalho, os conhecimentos relacionados à natureza do conhecimento científico são compreendidos como conteúdos metacientíficos.
} 
não deixe explícito a importância do conhecimento do contexto ${ }^{5}$ no desenvolvimento do PCK, ele reconhece a sua relevância ao colocá-lo como um dos sete conhecimentos ${ }^{6}$ que fazem parte da base de ensino do professor. Na nossa compreensão, como destacamos na Fig. 1, o conhecimento do contexto é enaltecido na mobilização do PCK. Apesar de, no nosso entendimento do PCK, destacarmos os conhecimentos do conteúdo, pedagógico geral e do contexto, esclarecemos que os demais conhecimentos da base de ensino do professor estão em constante diálogo entre si.

Em especial, não o consideramos como um conjunto de conhecimentos fixos dos professores, assimilados durante os seus processos de formação, sejam eles iniciais ou continuados. Mas, como conhecimentos que podem ser construídos a partir da reflexão de novas experiências de ensino dos professores (novatos ou experientes).

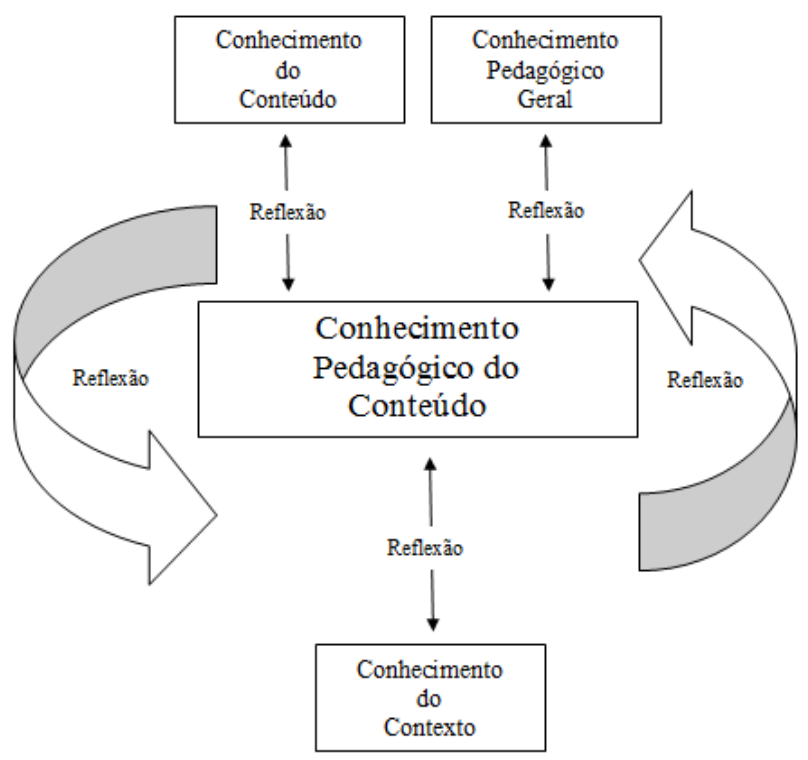

Fig. 1 - Transformação do PCK. Fonte: Extraído de [SILVA, 2018, p. 67].

Portanto, nossa compreensão é que, principalmente na formação inicial, o PCK de futuros professores de Física pode ser entendido como instável e cíclico, no qual a reflexão ${ }^{7}$ em torno de situações de ensino e aprendizagem podem se tornar momentos oportunos para a sua mobilização.

\footnotetext{
5 Para Shulman, o conhecimento do contexto refere-se ao conhecimento do funcionamento dos grupos na aula, a gestão e financiamento dos distritos escolares e as características das comunidades e culturas.

6 Para Shulman, os setes conhecimentos que fazem parte da base de ensino do professor são: Conhecimento de Conteúdo, Pedagógico Geral, Pedagógico do Conteúdo, dos Aprendizes, Curricular, dos Contextos Educacionais e dos Fins Educacionais.

${ }^{7}$ Em outro trabalho foi desenvolvido um estudo que busca compreender como o processo de reflexão pode contribuir no desenvolvimento do PCK de futuros professores de Física (SILVA; MARTINS, 2018a).
} 
Sendo assim, neste trabalho, buscamos investigar como os conhecimentos de futuros professores de Física relacionados à compreensão de Ciência dos estudantes, às estratégias instrucionais, ao currículo de Ciências e à avaliação contribuem para a mobilização do conhecimento pedagógico do conteúdo referente à temática Natureza da Ciência (PCK/NdC), principalmente quando são solicitados a construírem estratégias didáticas que visam o ensino de conteúdos metacientíficos na Educação Básica.

A seguir, procuramos, com base na literatura especializada, abordar a discussão sobre o que seria o PCK/NdC.

\section{O que é o PCK/NdC ${ }^{8}$ ?}

Lederman (2002) ressalta que as relações existentes entre os conteúdos relativos à Natureza da Ciência ( $\mathrm{NdC}$ ) e o seu ensino são incertas. Embora seja possível melhorar a compreensão dos professores de Ciência acerca de aspectos da $\mathrm{NdC}$ nas suas formações, os conhecimentos pedagógicos atrelados ao ensino destes aspectos são ainda pouco debatidos. Umas das conclusões dos investigadores é que este fato leva à produção de propostas de ensino pouco consistentes no que diz respeito à aprendizagem dos estudantes da Educação Básica.

Para Abd-El-Khalick, Bell e Lederman (1998), o PCK/NdC refere-se aos conhecimentos dos professores sobre os caminhos e representações didáticas que tornam possível a aprendizagem de aspectos da $\mathrm{NdC}$ pelos estudantes.

Um ponto que Lederman (2007) e Hanuscin, Lee e Akerson (2010) chamam a atenção é a falta de estudos sobre a origem, natureza e desenvolvimento do $\mathrm{PCK} / \mathrm{NdC}$ ou de propostas que pretendam compreender como ele se mobiliza nos professores, sejam eles em formação ou em exercício. Contudo, na literatura é possível encontrar algumas propostas neste sentido, por exemplo, Hanuscin, Lee e Akerson (2010), baseando-se no modelo proposto por Magnusson, Borko e Krajcik (1999), apresentam um modelo de PCK/NdC para professores, tal como exposto na Fig. 2.

No modelo proposto, as investigadoras procuram compreender como se dá a mobilização do PCK/NdC em professores de Ciências no ensino fundamental, mostrando possíveis relações que podem existir entre os diferentes conhecimentos que os professores possuem. Outro modelo de PCK/NdC, também inspirado no trabalho de Magnusson, Borko e Krajcik (1999), é apresentado por Demirdogen e Uzuntiryaki-Kondakçl (2016). As investigadoras buscam compreender como ocorre a mobilização do $\mathrm{PCK} / \mathrm{NdC}$ de futuros professores de Química durante um curso de formação. Na Fig. 3, apresentamos a proposta.

\footnotetext{
${ }^{8}$ Embora o termo PCK/NdC reúna dois acrônimos oriundos de idiomas diferentes, eles remetem a siglas amplamente reconhecidas na literatura da área de ensino de ciências. Por essa razão, optamos, nesse trabalho, não fazer a tradução do termo PCK.
} 


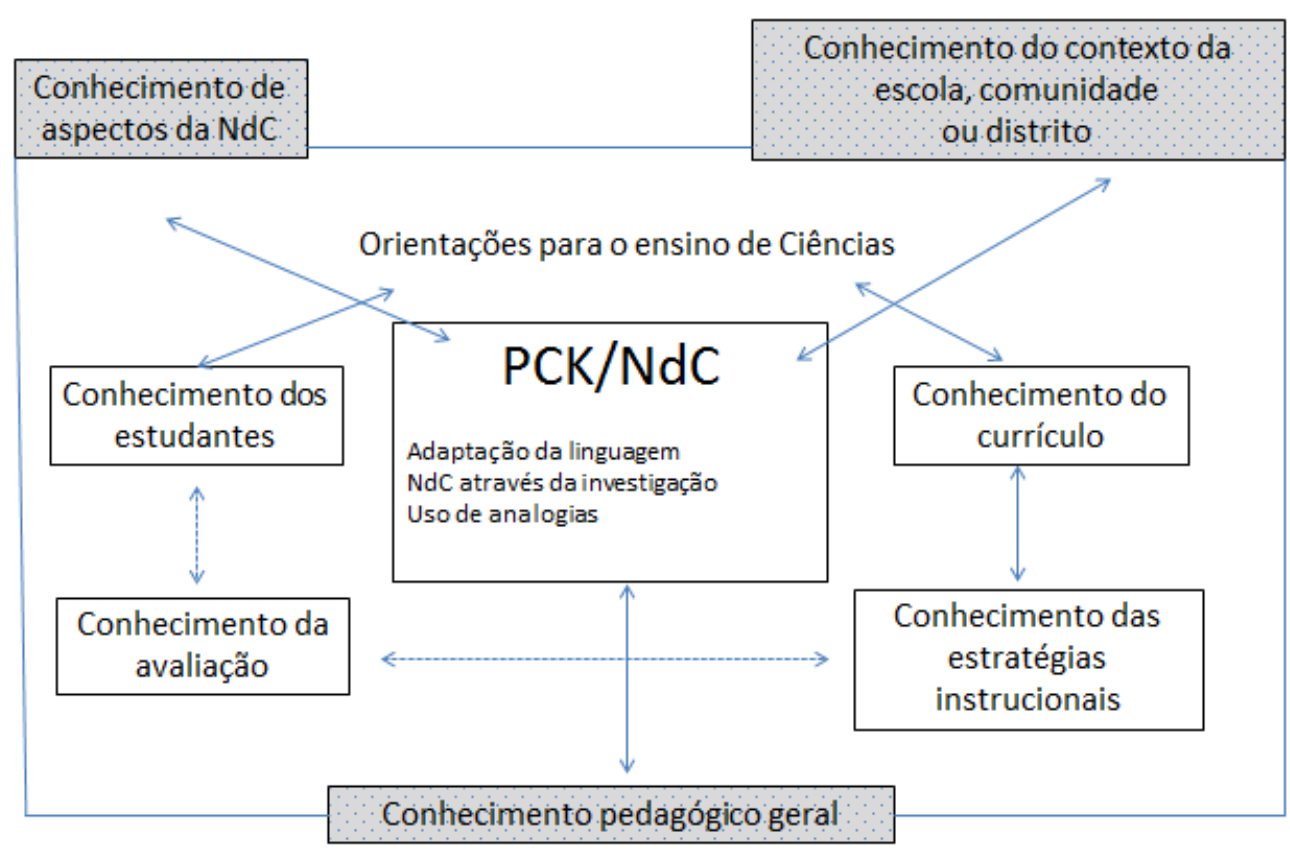

Fig. 2 - Proposta de PCK/NdC de professores de Ciências.

Fonte: [Hanuscin; Lee; Akerson, 2010, p.160, tradução nossa.]

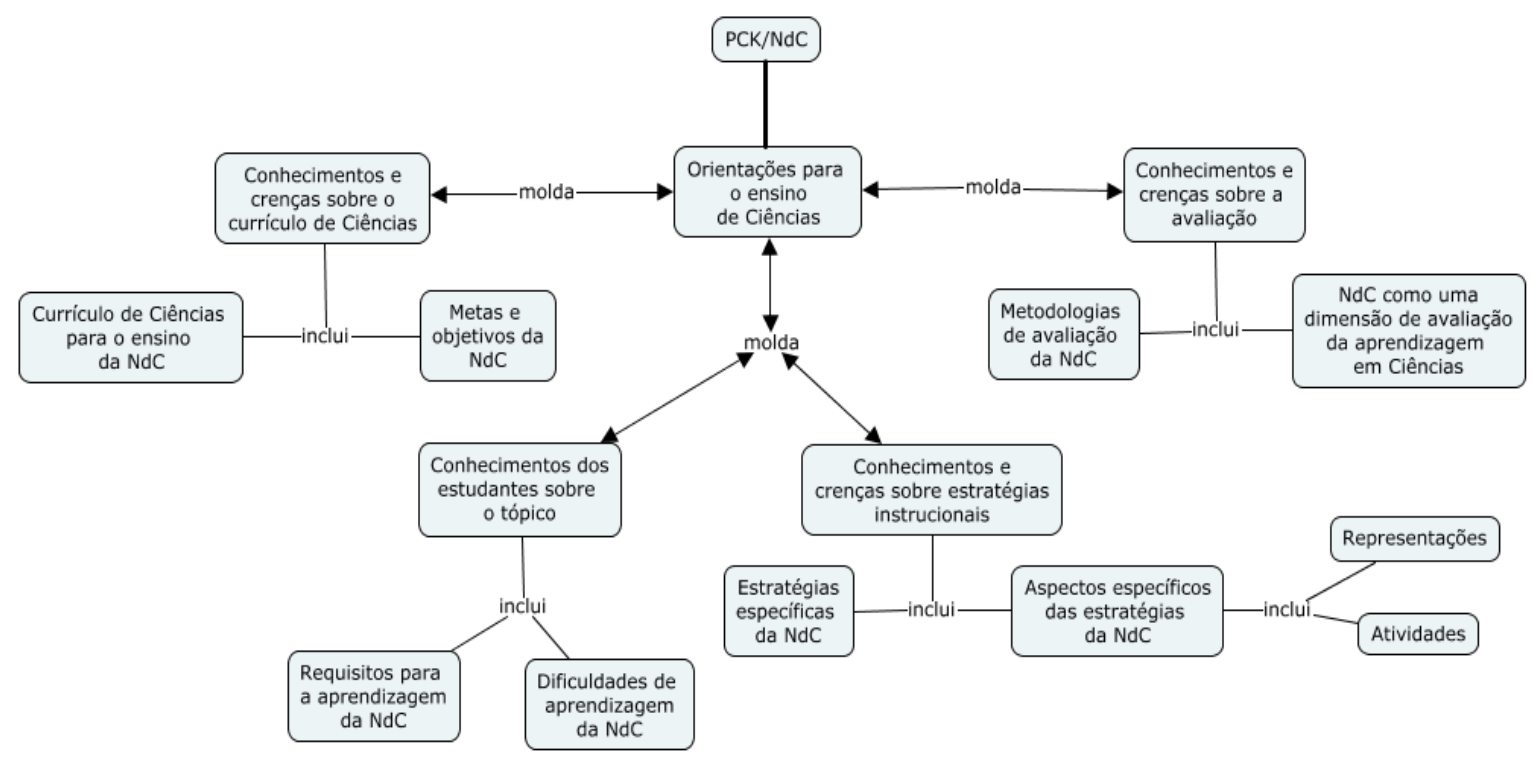

Fig. 3 - Proposta de PCK/NdC de futuros professores de Química Fonte: [Demirdogen e Uzuntiryaki-Kondakçl, 2016, p.4, tradução nossa]

Recentemente, propusemos [Silva; Martins, 2018b] um modelo de avaliação do PCK/NdC, o qual foi utilizado em um estudo com futuros professores de Física. Sentimos essa necessidade devido à falta de pesquisas que buscassem compreender a natureza da mobilização do PCK/NdC no público exposto. No trabalho citado, esclarecemos, detalhadamente, 
a necessidade da existência de uma nova proposta. Aqui, de forma resumida, destacamos alguns pontos:

1. A falta de conexão entre os conhecimentos da base de ensino e, também, dos componentes que fazem parte do $\mathrm{PCK} / \mathrm{NdC}$.

Este ponto é alvo de críticas desde os primeiros modelos de $\mathrm{PCK}^{9}$. Por exemplo, em Demirdogen e Uzuntiryaki-Kondakçl (2016), cf. Fig. 3, os componentes da proposta não são conectados. Eles não dialogam constantemente entre si. Diferentemente do que podemos observar na proposta Hanuscin, Lee e Akerson (2010), exposta na Fig. 2.

2. A exclusão de fatores não cognitivos na proposta, como, por exemplo, afetividade, emoção, sentimentos e motivação.

Neste ponto, como argumentam Garritz e Mellado (2014), o domínio afetivo é inserido dentro do conhecimento pedagógico geral. Eles chamam a atenção que esse elemento é muitas vezes utilizado também para motivar e guiar os estudantes em toda a aprendizagem de disciplinas específicas. A falta deste domínio no PCK também fez Shulman refletir, posteriormente. Para ele:

[...] os conhecimentos dos aspectos afetivos do professor e a ação são ambos importantes porque muito do que os professores sabem e fazem são conectados pelos seus próprios estados de afetividade e emoção, assim como sua habilidade para influenciar os sentimentos, motivação, persistência e identificar processos de formação de seus estudantes (SHULMAN, 2015, p. 9, tradução nossa).

Como podemos notar, esse fator, que foi alvo de críticas à proposta original de Shulman, fazendo-o refletir posteriormente, também não ganha corpo nos modelos apresentados acima, o quede certa maneira valida a proposição de um modelo, conforme mostramos na Fig. 4 .

Na proposta de (Silva e Martins, 2018b), também inspirada no trabalho de Magnusson, Borko e Krajcik (1999), foi idealizado que o PCK/NdC é formado, essencialmente, por dois tipos de conhecimentos, a saber: (a) ligantes: Orientações para o ensino de conteúdos metacientíficos e Reflexão Colaborativa e (b) conhecimentos efetivos: Conhecimento da compreensão de Ciência dos estudantes da Educação Básica, conhecimento das estratégias instrucionais para o ensino de conteúdos metacientíficos, conhecimentos do currículo de Ciências para ensinar conteúdos metacientíficos e conhecimentos da avaliação de conteúdos metacientíficos. Para um melhor entendimento deles, sugerimos a consulta ao quadro 1.

\footnotetext{
9 Vale ressaltar que, mesmo Shulman sendo considerado "pai" do PCK, ele nunca desenvolveu um modelo de PCK propriamente dito.
} 


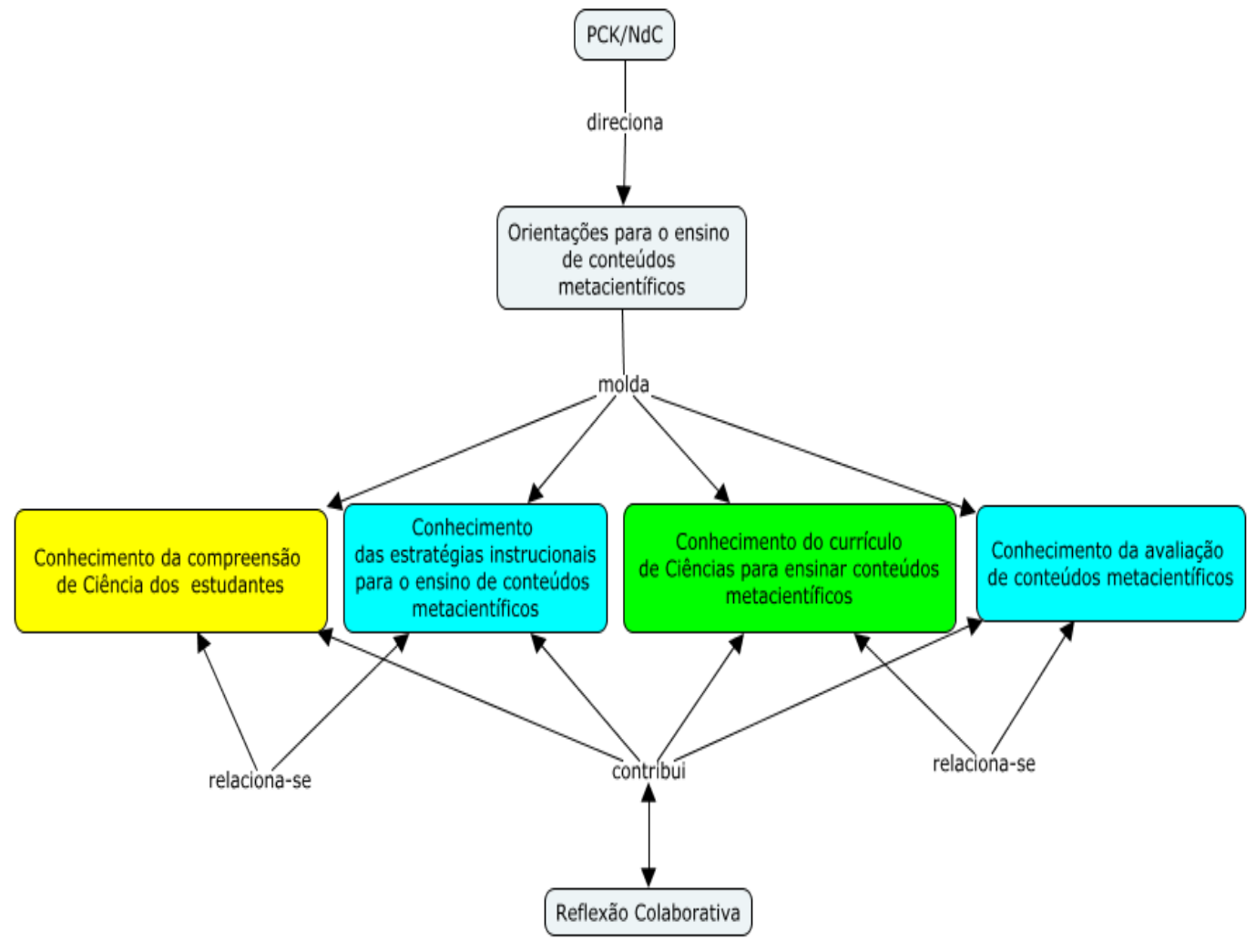

Fig. 4 - Proposta de modelo avaliativo para o PCK/NdC de futuros professores de Física. Fonte: [SILVA; MARTINS, 2018b, p. 399]

Quadro 1 - Conhecimentos efetivos do PCK/NdC.

\begin{tabular}{|l|l|}
\hline \multicolumn{1}{|c|}{ Conhecimento relacionado ao PCK/NdC } & \multicolumn{1}{c|}{ Descrição sucinta } \\
\hline $\begin{array}{l}\text { Conhecimento da compreensão de Ciência dos estu- } \\
\text { dantes da Educação Básica }\end{array}$ & $\begin{array}{l}\text { Configuram-se como os conhecimentos dos professo- } \\
\text { res sobre a compreensão dos estudantes sobre a Ciên- } \\
\text { cia, conhecimentos prévios e dificuldades de aprendi- } \\
\text { zagem relacionadas aos conhecimentos metacientífi- } \\
\text { cos. }\end{array}$ \\
\hline $\begin{array}{l}\text { Conhecimento das estratégias instrucionais para o o } \\
\text { ensino de conteúdos metacientíficos }\end{array}$ & $\begin{array}{l}\text { Diz respeito ao conhecimento de estratégias didáticas } \\
\text { relacionadas aos conhecimentos metacientíficos, prin- } \\
\text { cipalmente suas potencialidades e dificuldades de } \\
\text { inserção. }\end{array}$ \\
\hline $\begin{array}{l}\text { Conhecimento do currículo de Ciências para ensinar } \\
\text { conteúdos metacientíficos }\end{array}$ & $\begin{array}{l}\text { Este componente compreende o conhecimento que os } \\
\text { professores necessitam possuir sobre as metas e obje- } \\
\text { tivos de aprendizagens dos alunos em relação aos } \\
\text { conhecimentos metacientíficos que desejam lecionar. }\end{array}$ \\
\hline $\begin{array}{l}\text { Conhecimento da avaliação de conteúdos metacientí- } \\
\text { ficos }\end{array}$ & $\begin{array}{l}\text { Ele constitui-se como os elementos de metodologias } \\
\text { de avaliação das aprendizagens de conhecimentos } \\
\text { metacientíficos, que são aprendidos e vivenciados } \\
\text { pelos futuros professores de Física na sua formação } \\
\text { inicial. Nele, ele encontra exemplos e orientações de } \\
\text { propostas de avaliação específicas para a situação, } \\
\text { decorrentes, principalmente de experiências formati- } \\
\text { vas. }\end{array}$ \\
\hline
\end{tabular}

Fonte: Elaborado com base em [SILVA; MARTINS, 2018b]. 
Na proposta supracitada, o problema da exclusão de fatores não cognitivos é solucionado com a propositura da reflexão colaborativa, a qual abarca fatores como afetividade na mobilização do PCK/NdC. Conforme destacamos na Fig. 4, ela também serve como ligação entre conhecimentos do próprio $\mathrm{PCK} / \mathrm{NdC}$ dos professores. Especialmente, no diz respeito a este quesito, na Fig. 5, mostramos como o PCK/NdC dialoga com os demais componentes da base de ensino dos professores. Ou seja, apresentamos as relações do modelo exposto na Fig. 4 com os demais conhecimentos da base.

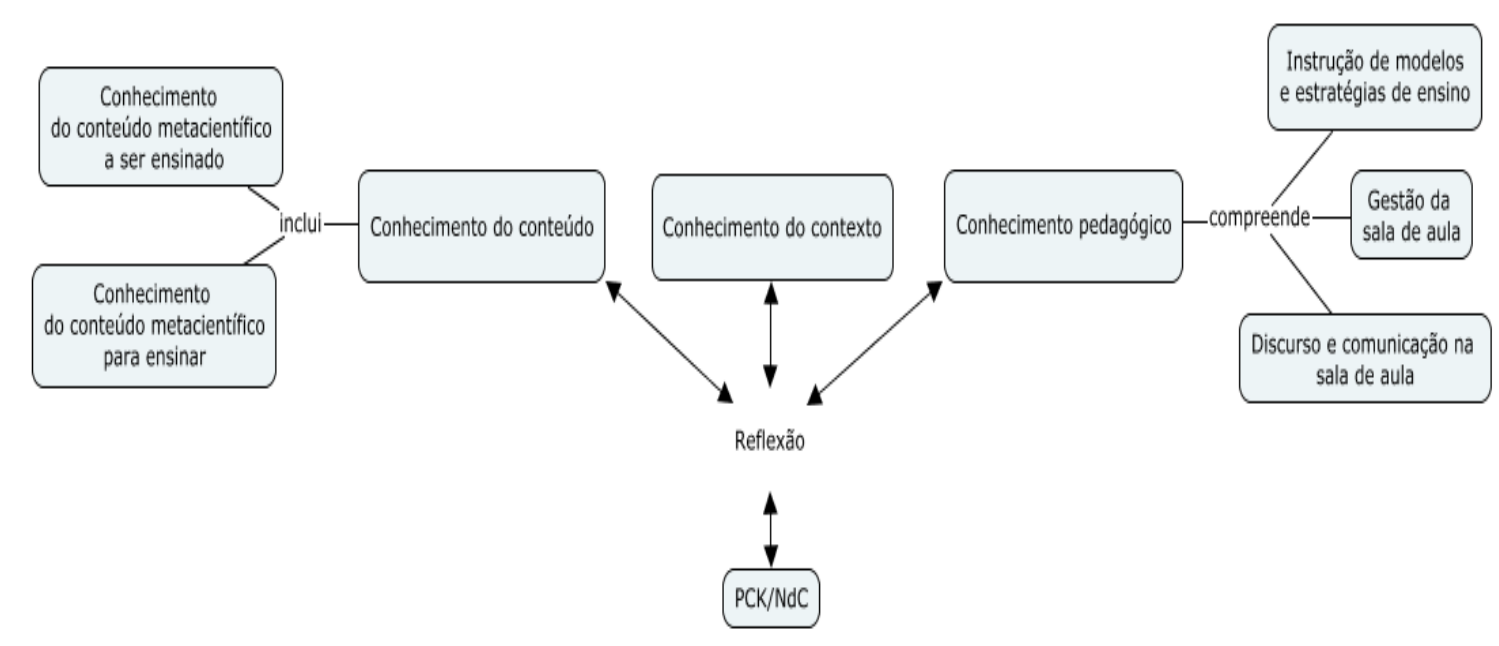

Fig. 5 - Transformação do PCK/NdC a partir do diálogo com outros conhecimentos da base de ensino. Fonte: Extraído de [SILVA; MARTINS, 2018b, p.397].

Ou seja, como destacado na Fig. 1 e ressaltado na Fig. 5, a reflexão ganha um maior destaque no processo de desenvolvimento do PCK/NdC.

Tendo como referência os aspectos teóricos discutidos até aqui, apresentamos, no próximo tópico, a metodologia de pesquisa do nosso estudo.

\section{Aspectos metodológicos do estudo}

Na nossa pesquisa, buscamos investigar questões relativas ao ensino de temas relacionados à natureza do conhecimento científico com futuros professores de Física. Participaram da investigação 9 (nove) licenciandos de uma universidade pública brasileira, matriculados em uma disciplina de Evolução Histórica da Física que possibilitava discussões de cunho didático, histórico e epistemológico da Física.

Conforme destaca Marconi (2003), o nosso estudo se define como qualitativo, pois se observou nele: (a) preocupação com o processo desenvolvido, e não simplesmente com o produto final; (b) contato direto do pesquisador com o local que está sendo investigado; (c) os dados coletados são, quase exclusivamente, descritivos: gravações, entrevistas, entre outros; e 
(d) a variedade de pontos de vista. Além disso, configura-se como um estudo de natureza interpretativa. Conforme descreve Moreira (2011), o foco deste tipo de pesquisa se encontra na

\begin{abstract}
[...] interpretação dos significados atribuídos pelos sujeitos às suas ações em uma realidade socialmente construída, através de observação participativa, isto é, o pesquisador fica imerso no fenômeno de interesse. Os dados obtidos por meio dessa participação são de natureza qualitativa e analisados de forma correspondente (MOREIRA, 2011, p. 76).
\end{abstract}

Desta forma, com base no nosso estudo, intentamos responder as seguintes questões: (1) Como os conhecimentos da compreensão de Ciência dos estudantes da Educação Básica influenciam na mobilização do PCK/NdC?; (2) Como os conhecimentos das estratégias instrucionais de conteúdos metacientíficos influenciam na mobilização do PCK/NdC?; (3) Como o conhecimento do currículo de Ciências influencia na mobilização do PCK/NdC? e (4) Como o conhecimento de avaliação de conteúdos metacientíficos influencia na mobilização do PCK/NdC de futuros professores de Física?

No transcorrer da pesquisa, fizemos aportes dos seguintes elementos metodológi$\cos ^{10}$ : pesquisa bibliográfica, questionário, diário de reflexão dos participantes da pesquisa e entrevista semi-estruturada. Assim, foram coletados dados descritivos, transcrições de entrevistas e relatos dos diários de reflexão dos participantes.

O diário de reflexão se configurou como um momento no qual foi possível a narração de dúvidas, tensões e anseios no decorrer da pesquisa. Devido a sua característica, configurou-se também como outra possibilidade de reflexão sobre o desenvolvimento de ideias dos sujeitos relacionadas às atividades de cunho metacientífico e sua inserção na sala de aula, possibilitando-nos, em especial, uma ferramenta de acesso aos indícios do desenvolvimento dos PCK/NdC. Além da livre narração dos participantes, sugerimos alguns questionamentos para reflexão, que podem ser vistos no anexo $\mathrm{A}$.

No nosso trabalho, as entrevistas foram, também, uma das principais ferramentas para acesso do $\mathrm{PCK} / \mathrm{NdC}$. Propusemos três entrevistas, em forma de roteiros, com respectivamente dez, sete e seis questões, como destacadas no anexo B. Elas tinham por objetivo, em momentos distintos da pesquisa, investigar como o PCK/NdC foi mobilizado pelos participantes, a partir da construção das atividades de cunho histórico e epistemológico na disciplina de Evolução Histórica da Física e, em especial, quais e como os conhecimentos que fazem parte do PCK/NdC afloravam nesses distintos momentos da investigação.

Na nossa pesquisa, utilizamos dois questionários. Foram eles: (a) Caracterização Inicial dos participantes ${ }^{11}$ e (b) Representação de Conteúdos. O questionário de Caracterização

\footnotetext{
${ }^{10}$ Kind (2009) destaca que pesquisas (ver, por exemplo: Abd-El-Khalick; Bell; Lederman, 1998; Hanuscin; Lee; Akerson, 2010; Demirdogen e Uzuntiryaki-Kondakçl, 2016) que buscam estudar a natureza do PCK caracterizam-se pela pluralidade de elementos metodológicos. Para a pesquisadora, esse fato é explicado devido à própria complexidade do acesso à natureza do objeto de estudo, principalmente devido à sua natura tácita.
}

11 Por ser um questionário introdutório e extenso, sugerimos que sua consulta seja feita em (Silva, 2018). 
Inicial dos participantes teve por objetivo traçar as experiências dos participantes relacionadas ao ensino e aprendizagem da Física e captara possível presença de elementos que se caracterizam como indícios do $\mathrm{PCK} / \mathrm{NdC}$, no início da pesquisa. Outro questionário foi o $\boldsymbol{R e}$ presentação de Conteúdos (CoRe). Ele foi construído por Loughran, Mulhall e Berry (2004) e foi adaptado no nosso estudo. $\mathrm{O}$ instrumento tem por objetivo investigar a presença de elementos do PCK/NdC nos participantes da pesquisa e pode ser visto no quadro 2.

Quadro 2 - Representação de Conteúdos (CoRe).

\begin{tabular}{|c|c|c|c|}
\hline \multicolumn{4}{|l|}{ Tema e (ou) questão(ões) sobre a Ciência abordado ${ }^{12}$ : } \\
\hline Questões do Core & Ideia 1 & Ideia 2 & Outras \\
\hline $\begin{array}{l}\text { 1. O que você pretende que os estudantes aprendam sobre essa } \\
\text { ideia? }\end{array}$ & & & \\
\hline 2. Por que é importante para o estudante aprender essa ideia? & & & \\
\hline 3. O que você sabe a mais sobre essa ideia? & & & \\
\hline $\begin{array}{l}\text { 4. Quais são as dificuldade e limitações ligadas ao ensino dessa } \\
\text { ideia? }\end{array}$ & & & \\
\hline $\begin{array}{l}\text { 5. Que conhecimento sobre o pensamento dos estudantes tem } \\
\text { influência no seu ensino sobre essa ideia? }\end{array}$ & & & \\
\hline 6. Que outros fatores influenciam no ensino desta ideia? & & & \\
\hline $\begin{array}{l}\text { 7. Que procedimentos/estratégias você emprega para que os alu- } \\
\text { nos se comprometam com essa ideia? }\end{array}$ & & & \\
\hline $\begin{array}{l}\text { 8. Que maneiras específicas você utiliza para avaliar a compreen- } \\
\text { são dos alunos sobre essa ideia? }\end{array}$ & & & \\
\hline
\end{tabular}

Fonte: Adaptado de Loughran; Mulhall e Berry (2004).

Na investigação, os processos de captação e análise dos dados encontram-se entrelaçados, ou seja, ocorreram simultaneamente durante o transcorrer da disciplina, conforme destaca Gibbs (2009). Assim, buscamos a organização do material, dividindo-o em categorias e, posteriormente, a procura de relações entre essas categorias.

No estudo, a análise de conteúdo de Bardin (2009) foi empregada para identificação, seleção, classificação e categorização dos dados disponibilizados de maneira descritiva e interpretativa nas entrevistas, questionários e microaulas.

Na fase de pré-análise, após a definição do corpus de análise (questionários, entrevistas e diário de reflexão), estabelecemos um contato inicial com os documentos a serem analisados, tomando como referência as categorias mais gerais que emergiram diretamente dos estudos na literatura e, mais especificamente, do modelo proposto por Silva e Martins (2018b), exposto na Fig. 4. Uma segunda leitura tinha por intuito a triangulação dos registros,

\footnotetext{
12 Esta parte foi adicionada ao CoRe devido à característica da pesquisa que foi desenvolvida.
} 
conforme pode ser visto na Fig. 6. Nessa fase, emergiram as subcategorias. Durante todo esse processo, buscávamos apoio da literatura especializada em torno de respostas para as questões da nossa pesquisa.

Em relação às entrevistas, houve gravação dos áudios e, posteriormente, fizemos as transcrições. No intuito de assegurar a qualidade e validação do estudo, apesar da confidencialidade e anonimato dos participantes, o conteúdo das transcrições foi devolvido aos mesmos, para que pudessem fazer a análise prévia de seus conteúdos. Esperávamos, assim, garantir a integralidade e veracidade das transcrições dos dados.

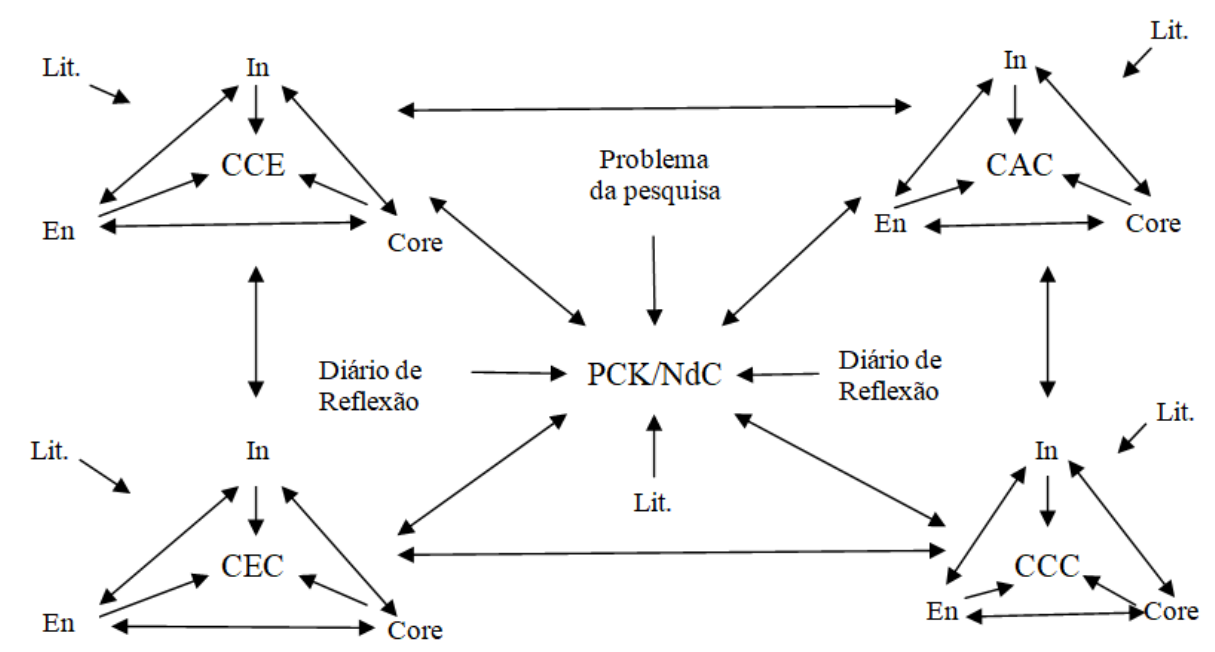

Legenda: CCE - Conhecimento da compreensão de Ciências dos estudantes; CEC - Conhecimento das estratégias instrucionais para o ensino de conteúdos metacientíficos; CCC - Conhecimento do currículo de Ciências para ensinar conteúdos metacientíficos; CAC - Conhecimento da avaliação de conteúdos metacientíficos; Lit. Literatura In - Questionário de caracterização inicial dos participantes; En- Entrevistas e Core - Representação de Conteúdos.

Fig. 6 - Triangulação múltipla dos instrumentos de coleta de dados. Fonte: (Silva, 2018).

No próximo tópico, fazemos a análise dos nossos dados.

\section{A análise do PCK/NdC de futuros professores de Física}

\section{1 A influência do Conhecimento da compreensão de Ciência dos estudantes da Edu- cação Básica}

Conforme já destacamos, o estudo se propôs a investigar indícios da mobilização do PCK/NdC de professores de Física, principalmente diante de situações de ensino e aprendizagem na sua formação inicial.

Definimos este conhecimento que os futuros professores de Física devem possuir sobre a compreensão dos estudantes da Educação Básica sobre a Ciência. Ele perpassa pela 
compreensão de concepções prévias, dificuldades de aprendizagem e crenças sobre as possibilidades dos seus estudantes de aprenderem ou não sobre o conteúdo a ser discutido.

A partir dos dados extraídos, conforme mostramos a seguir, notamos que este conhecimento também mantém relações tanto com as características dos estudantes e o contexto no qual as atividades são aplicadas, como também a construção do conhecimento de conteúdos metacientíficos dos futuros professores.

As informações disponibilizadas pelos futuros professores de Física, por meio da triangulação do questionário de caracterização inicial dos participantes, entrevistas e o instrumento de representação de conteúdos (CoRe), possibilitaram a construção deste tópico, o qual buscou problematizar as influências do conhecimento da compreensão de Ciência dos estudantes da Educação Básica. Para manter o anonimato dos participantes utilizamos nomes fictícios. Agora, devido à pluralidade de instrumentos de coleta de dados utilizados neste e nos próximos tópicos, utilizaremos, atrelado ao nome dos participantes da pesquisa, um código que identifica a fonte de sua fala, como, por exemplo:

Ricardo: É muito importante uma introdução, uma história. Por exemplo, tem uma mocinha que trabalha comigo. Ela chegou para mim e perguntou o que é a Física. Ela tava (sic) na escola e tal. (EN1).

Ou seja, neste caso, o recorte da fala de Ricardo encontra-se na entrevista 1. Para os demais instrumentos de coleta de dados, seguiremos a codificação apresentada no quadro a seguir:

Quadro 3 - Códigos de identificação das fontes dos dados.

\begin{tabular}{|c|c|}
\hline Fonte do Excerto & Código de Identificação \\
\hline $\begin{array}{c}\text { Questionário de caracterização inicial dos partici- } \\
\text { pantes }\end{array}$ & QCI \\
\hline Representação do Conteúdo & CoRe \\
\hline Entrevista 1 e 2 & EN1 e EN2 \\
\hline Entrevista Final & ENF \\
\hline
\end{tabular}

Fonte: Elaborado pelos autores do trabalho.

Tomando como base as fontes de dados contidas no quadro 3, que refletem as informações disponibilizadas pelos participantes da pesquisa, relacionadas às influências do "Conhecimento da compreensão de Ciência dos estudantes", e, principalmente, após o uso da técnica de análise de conteúdo de Bardin (2009), chegamos a quatro subcategorias emergentes, conforme podemos observar no quadro 4 . 
Quadro 4: Conhecimento da compreensão de Ciência dos estudantes da Educação Básica.

\begin{tabular}{|c|c|c|c|c|c|c|c|c|c|}
\hline \multirow[t]{2}{*}{ Categoria } & \multicolumn{9}{|c|}{$\begin{array}{c}\text { Presente no participante } \\
\text { da pesquisa }\end{array}$} \\
\hline & Ana & Diego & José & Lucas & Lúcia & Miguel & Paulo & Pedro & Ricardo \\
\hline $\begin{array}{l}\text { Interesse dos } \\
\text { alunos }\end{array}$ & & & $\mathrm{x}$ & $\mathrm{x}$ & & & $\mathrm{X}$ & $\mathrm{x}$ & \\
\hline $\begin{array}{l}\text { Habilidade dos } \\
\text { alunos em com- } \\
\text { preender o con- } \\
\text { teúdo }\end{array}$ & $\mathrm{X}$ & $\mathrm{X}$ & & $\mathrm{X}$ & & $\mathrm{x}$ & & & $\mathrm{x}$ \\
\hline $\begin{array}{l}\text { Imagem do pro- } \\
\text { fessor diante dos } \\
\text { alunos }\end{array}$ & $\mathrm{X}$ & & & $\mathrm{x}$ & $\mathrm{X}$ & $\mathrm{x}$ & & & $\mathrm{x}$ \\
\hline $\begin{array}{l}\text { Conhecimento } \\
\text { prévio dos alu- } \\
\text { nos }\end{array}$ & $\mathrm{X}$ & $\mathrm{X}$ & $\mathrm{X}$ & & $\mathrm{X}$ & & $\mathrm{x}$ & $\mathrm{x}$ & $\mathrm{x}$ \\
\hline
\end{tabular}

Fonte: Os autores.

O conhecimento da compreensão de Ciência dos estudantes, conforme (Silva e Martins, 2018b), se configura tanto como o conhecimento que os futuros professores de Física devem possuir sobre a compreensão dos estudantes sobre a Ciência, como de fatores atrelados à dificuldade de aprendizagem de conteúdos metacientíficos, oriundos destas compreensões, por exemplo: concepções inadequadas sobre a Ciência no livro didático de Ciências, influências de meios audiovisuais, incompreensões dos próprios professores, dentre outras.

Sobre (a) interesse dos alunos, notamos que este fator é substancial para o sucesso de atividades que busquem acessar a compreensão dos estudantes sobre aspectos da $\mathrm{NdC}$. $\mathrm{Ou}$ seja, na concepção dos futuros professores de Física da pesquisa, caso a atividade não seja interessante para os discentes, a possibilidade de fracasso na captação de suas ideias pode tornar-se uma tarefa complexa e com alto grau de insucesso, como podemos notar nas falas de José, Lucas Paulo e Pedro.

José: [...] Acho que o começo se dá pela compreensão do estudante sobre o que é a Ciência. Mas, eu tento buscar atividades que indiquem o que eles já sabem e que agradem o estudante e que possam demonstrar interesse para eles. (EN1).

Lucas: [...] Um sentimento de quase sempre não atingir os objetivos propostos. Cansado pela falta de interesse dos alunos e pela desvalorização do profissional. (QCI).

Paulo: [...] O interesse dos alunos é o ponto de partida para que eu possa compreender o que ele já sabe sobre o conteúdo. Então, acho que uma atividade inicial logo no começo da aula bem interessante e que possibilite o aluno responder com suas palavras pode ajudar nessa compreensão, professor. (EN2).

Pedro: [...] Primeiro achar uma forma de compreender o que ele já sabe sobre a Ciência, depois achar um texto, uma boa fonte histórica para incluir este novo conteúdo e de maneira que eu possa chamar a atenção dos alunos e incentivar o interesse deles pelo conteúdo. [...] A gente estuda muito o fato do processo ensino e 
aprendizagem. A gente sabe que o aluno vai saber de forma imediata também, se eu não sei o conteúdo ou a ideia deles sobre o mesmo. Então, a gente tem que se colocar empaticamente no lugar do aluno e tentar verificar suas dificuldades e interesses sobre o conteúdo. (EN2). [...] "Despertar o interesse dos alunos para saber o que ele já sabe sobre o conteúdo, a fim de corrigir erros historiográficos quanto à formação do conteúdo. (CoRe).

Sobre (b) habilidade dos alunos em compreender o conteúdo, Ana, Diego e Miguel relacionam a aprendizagem de conteúdos metacientíficos à habilidade de compreensão dos estudantes sobre estes conteúdos. Além disso, a compreensão inicial dos estudantes é um fator que, para os futuros professores de Física, aumenta a aprendizagem destes conteúdos, conforme observamos.

Ana:[...] Eu sei que os estudantes são influenciados com ideias de que os cientistas são loucos e são geniais, de modo que constroem os conhecimentos isolados e não necessitam de outras pessoas para desenvolverem suas ideias. Isso é o ponto de partida para compreender o que os estudantes já sabem sobre a NdC e será uma avaliação inicial que vai diminuir a dificuldade da compreensão dos estudantes.(CoRe). [...] O próprio conteúdo, em si, do que é a NdC já abrange muita coisa. Então, dentro do conceito, por exemplo, como os estudiosos viam o conceito abrange muita coisa e a habilidade do professor em ensinar e do estudante em aprender são importantes. (EN1).

Diego: [...] A dificuldade que eles têm em compreender o conteúdo reforça a imagem que eles já têm sobre como é a vida de um cientista, ou seja, como sendo uma pessoa isolada do resto do mundo e da sociedade, a ciência como não influenciando a vida cotidiana das pessoas. (CoRe).

Miguel: [...] Tem um pequeno problema no ensino médio. Mas, no ensino superior, não tem, porque nós já temos uma base ampla. Isso, no final do curso. Isso complica a aprendizagem dos estudantes, pois muitos alunos têm esse contexto que o cientista é aquele cara que é só o homem que fica no laboratório, fazendo experimento sem parar e é um pouco difícil mudar isso, acho. (EN1).

Por fim, Miguel chama a atenção para que a existência de uma possível base de compreensão inicial do conteúdo poderia tornar a habilidade de aprendizagem dos estudantes mais satisfatória. Contudo, como demonstram algumas pesquisas (ver, por exemplo: Lederman (1992; 2007) e Santos e colaboradores (2017)), em alguns casos, a concepção inicial dos estudantes, de todos os níveis, sobre aspectos da $\mathrm{NdC}$, é inadequada. Este fator, por si só, remete a uma atenção redobrada para a chamada de Miguel, pois remete, também, a um cuidado para que o professor não reforce estas concepções. Para tanto, torna-se importante, neste sentido, um desenvolvimento mais robusto do $\mathrm{PCK} / \mathrm{NdC}$ destes professores.

Sobre (c) imagem do professor diante dos alunos, Ana, Lúcia e Miguel deixam transparecer que a imagem deles, diante dos alunos, pode afetar a qualidade do ensino de conteú- 
dos metacientíficos. Ou seja, a complexidade e o ineditismo do conteúdo nas aulas de Física podem gerar possíveis conflitos nas práticas, abalando a confiabilidade dos alunos sobre os seus docentes, conforme notamos nas falas dos participantes.

\begin{abstract}
Ana: [...] Porque é muita coisa para saber. Tipo assim, o primeiro problema ia ser saber discutir bem o assunto, em si, e é isso um dos principais problemas. É muita coisa. Tentar estudar muito para saber bem para os alunos. [...] Eu ia sentir muita angustia, né... O aluno faz uma pergunta e eu não sei responder. É porque, até então, eu não tive contato com aquilo e nem com os alunos. É, tipo assim, um sentimento de fracasso. (EN1).

Lúcia: [...] É meio frustrante, né... Eu teria me preparado para dar determinada aula e o aluno vem com um conceito que eu talvez tenha visto, mas não tenha focado muito ou talvez não tenha estudado. Mas, eu diria que responderia na próxima aula. Por isso, é importante já conhecer o que aluno já sabe sobre a NdC. (EN1).

Miguel: [...] O conteúdo de NdC é complexo. No primeiro momento, eu ia falar que não ia saber. Mas, iria tentar trazer a resposta o mais breve possível. Ia ficar um pouco triste porque apesar de tanto estudo, vai ter sempre algumas perguntas que possivelmente eu não vou poder responder assim na hora. Isso prejudica a minha imagem como professor. [...] O primeiro momento ia ser um pouco de nervosismo, aí vem depois a tristeza de não saber responder aquela pergunta. Mas, eu ia ficar um pouco mais motivado em estudar mais para trazer aquela resposta e entender o que o aluno não entendeu ou que não sabia. (EN1).
\end{abstract}

Notamos que a relação entre o interesse dos alunos e a compreensão de Ciência dos seus futuros estudantes é um fator que pode obstaculizar, no princípio, atividades que busquem acessar, justamente, esta compreensão inicial dos estudantes da Educação Básica. Ou seja, para os futuros professores de Física, se a atividade não despertar a vontade dos seus discentes em fazê-la, possivelmente o seu resultado pode ser insatisfatório, trazendo-lhes poucas informações relevantes sobre a compreensão dos estudantes da Educação Básica. Assim, a elaboração de atividade que proporcionem o ensino de conteúdos metacientíficos ou a compreensão de Ciência dos estudantes do ensino médio parece sair da naturalidade das aulas de Física, causando possíveis confrontos ou sentimentos de angústia e desconfiança dos futuros professores de Física.

Ademais, notamos que o possível descrédito e desconfiança dos alunos da Educação Básica são fatores preponderantes para os futuros professores de Física. Esse fenômeno é abordado, também, em Garcia (1999) e Formosinho (2009). Os investigadores descrevem que os futuros professores ou professores com poucos anos de experiência, geralmente, mostram um alto grau de preocupação com sua imagem diante dos seus estudantes. Ou seja, buscam maneiras de serem reconhecidos por seus discentes como "bons" professores. Por outro lado, uma negativa pode trazer um misto de sentimentos de insucesso, como, por exemplo, os apresentados por Ana, Lúcia e Miguel. 
Por fim, sobre (d) Conhecimento prévio dos alunos, Ana, Diego, José, Lúcia, e Pedro chamam a atenção para a importância de conhecer o que seus estudantes sabem sobre aspectos da NdC. Para eles, esse tipo de compreensão torna-se de fundamental importância, principalmente, para a construção de estratégias didáticas mais coerentes com o perfil dos estudantes da Educação Básica, como podemos observar nas suas falas.

Ana: [...] Bem... A princípio, eu iria tentar saber o que eles pensam em relação à Ciência. Eu preciso saber disso. Eu acho que ia sentir medo, a princípio, da relação deles, se eles iam gostar ou não de estudar. (EN1).

Diego: [...] As dificuldades são justamente as concepções dos alunos em relação à Ciência. (CoRe).

José: [...] O conhecimento prévio dos estudantes sobre o conteúdo é importante como fator inicial de uma aula, principalmente sobre a NdC, que é pouco discutido em sala de aula. Eu preciso saber o que o meu aluno sabe antes de começar uma aula. (ENF).

Lúcia: [...] Eu gostaria de fazer uma sondagem com os alunos para saber o que eles pensam acerca de Ciência, história da Ciência, como é que se desenvolve. Procuro só para conhecer a mentalidade deles desse conceito. (EN1).

Pedro: [...] Como é que eu iniciaria... Acho que a melhor forma de se iniciar, além da apresentação do tema, seria com uma pergunta problema sobre o assunto abordado e a partir disso saber o que o aluno já sabe sobre a NdC. (EN1).

Dessa forma, compreendemos que a construção do Conhecimento da compreensão de Ciência dos estudantes, do grupo investigado, pode estar relacionada, primeiramente, ao conhecimento prévio dos alunos, o que compete, em maior grau, às discussões e vivências oportunizadas aos futuros professores de Física nas suas formações iniciais. Diante desse conhecimento prévio dos alunos, a elaboração de atividades mais próximas da realidade dos estudantes da Educação Básica seria facilitada, principalmente no que diz respeito às suas dificuldades de aprendizagem.

No próximo tópico, analisamos que fatores contribuem ou dificultam para a construção do conhecimento das estratégias instrucionais para o ensino de conteúdos metacientíficos.

\section{IV.2 A influência do Conhecimento das estratégias instrucionais para o ensino de conte- údos metacientíficos}

No modelo de avaliação para o PCK/NdC, Silva e Martins (2018b) destacam que o conhecimento das estratégias instrucionais para o ensino de conteúdos metacientíficos tem por finalidade fornecer, ao futuro professor de Física, conhecimentos relacionados às propostas de inserção de conteúdos metacientíficos na sala de aula. Neste tópico, buscamos investigar alguns fatores que favorecem ou dificultam a construção deste conhecimento na formação inicial de professores de Física, os quais destacamos no quadro 5. 
Quadro 5: Conhecimento das estratégias instrucionais para o ensino de conteúdos metacientíficos.

\begin{tabular}{|l|c|c|c|c|c|c|c|c|c|}
\hline \multirow{2}{*}{ Categoria } & \multicolumn{7}{|c|}{ Presente no participante } \\
\cline { 2 - 11 } & Ana & Diego & José & Lucas & Lúcia & Miguel & Paulo & Pedro & Ricardo \\
\hline $\begin{array}{l}\text { Conhecimento } \\
\text { prévio }\end{array}$ & & & $\mathrm{x}$ & & $\mathrm{x}$ & & & & $\mathrm{x}$ \\
\hline $\begin{array}{l}\text { Interesse dos } \\
\text { alunos }\end{array}$ & & $\mathrm{x}$ & & & & $\mathrm{x}$ & & \\
\hline $\begin{array}{l}\text { Importância do } \\
\text { visual }\end{array}$ & & & $\mathrm{x}$ & & $\mathrm{x}$ & & & & \\
\hline $\begin{array}{l}\text { Satisfação dos } \\
\text { estudantes }\end{array}$ & $\mathrm{x}$ & & $\mathrm{x}$ & & & $\mathrm{x}$ & $\mathrm{x}$ & & \\
\hline $\begin{array}{l}\text { Efetividade do } \\
\text { texto histórico }\end{array}$ & $\mathrm{x}$ & $\mathrm{x}$ & & $\mathrm{x}$ & & & $\mathrm{x}$ & $\mathrm{x}$ & \\
\hline $\begin{array}{l}\text { Conceitos relaci- } \\
\text { onados à NdC }\end{array}$ & & $\mathrm{x}$ & & & & & & & \\
\hline $\begin{array}{l}\text { Tempo das aulas } \\
\text { de Física }\end{array}$ & & $\mathrm{x}$ & & $\mathrm{x}$ & $\mathrm{x}$ & & $\mathrm{x}$ & $\mathrm{x}$ & \\
\hline $\begin{array}{l}\text { Atividades lúdi- } \\
\text { cas }\end{array}$ & $\mathrm{x}$ & & & & & & & & \\
\hline
\end{tabular}

Fonte: Os autores.

Sobre o (a) conhecimento prévio, José, Lúcia e Ricardo destacam a importância da compreensão do que o seu futuro discente sabe ou não sobre aspectos da NdC. José enaltece esse fator como um dos que possibilitam a criação de estratégias didáticas e aulas mais atraentes, como observamos nas falas a seguir.

José: [...] O conhecimento dos estudantes é bastante influente quando fala-se de aplicar uma nova metodologia ou conteúdo novo. Na aplicação deste tema em sala de aula, o pensamento do estudante ou conhecimento prévio observado no aluno é capaz de promover a desenvoltura da aula de maneira mais atrativa para a turma. Portanto, um conhecimento prévio sobre influências históricas e sociais causadas pela Ciência são bastante bem-vindas para a construção de minha atividade. (CoRe, grifo nosso).

Lúcia: [...] Para desenvolver minha atividade, eu sempre busco o conhecimento prévio que o aluno poderia ter sobre a $\mathrm{NdC}$. (EN2).

Ricardo: [...] Geralmente, eu ia começar perguntando para os alunos se eles tinham noção o que é Ciência. Esse é o ponto inicial para a construção de minha atividade. (EN1).

Notem que este fator também foi destaque na construção do conhecimento da compreensão de Ciência dos estudantes, algo que vai ao encontro do que destacam Silva e Martins (2018b), principalmente no que diz respeito às relações existentes entre conhecimentos efetivos do PCK/NdC, conforme pode ser visto na Fig. 4. 
Sobre (b) o interesse dos alunos, igualmente ao elemento anterior, ele aparece como um fator de possível construção de ambos os conhecimentos (compreensão de Ciência dos estudantes e estratégias instrucionais para o ensino de conteúdos metacientíficos). Uma das principais críticas às pesquisas que envolvem o PCK dá-se, justamente, pela falta tanto de evidências de relações existentes entre os demais conhecimentos da base para o ensino e o PCK, quanto dos conhecimentos que fazem parte do próprio PCK (KIND, 2009). Em nossa investigação, encontramos alguns elementos que fazem parte de distintos conhecimentos efetivos do PCK/NdC, como os dois destacados acima.

Sobre (c) a importância do visual, José e Lúcia destacam o uso de recursos visuais como outro fator relevante para a construção de estratégias didáticas, como pode ser observado:

José: [...]Eu estou pensando em dois recursos, que seriam o vídeo e, no caso, também, os textos didáticos. Por quê? Porque eu vejo que hoje em dia, o aluno está muito no visual. Aquela questão do visual e do toque, que é justamente o que as novas tecnologias estão trazendo. Para o aluno observar algo é mais fácil do que ele interpretar. Então, acho que trazer o visual, associar a algo mais próximo do aluno, para ele interpretar aquele conceito, é algo bastante visual.(EN1)

Lúcia: [...]Eu penso em trabalhar com a História da Astronomia. Acho que uma aula com várias imagens ou até vídeos curtos seriam interessantes para mostrar as diferenças entre os dois modelos. (EN1).

Sobre (d) a satisfação dos estudantes, Ana, José e Miguel destacam a importância de a atividade ser potencialmente agradável para os alunos, conforme notamos nas suas falas. $\mathrm{Ou}$ seja, para eles, existe uma possível relação entre o grau de comprometimento dos estudantes na atividade e o grau de satisfação dos mesmos.

Ana: [...] Quando estou preparando uma atividade, sempre penso como meu aluno vai receber. Principalmente uma tarefa que envolva a NdC, que é algo novo para mim e acho que também será para ele. Uma tarefa que não agrada o aluno, ele não faz direito. (EN1)

José: [...] Eu me sentiria tranquilo, porque já aconteceu comigo. Mas, percebi que o aluno não se sentiu confiante ao ver a atividade. Por isso, sempre faço uma atividade que possa agradá-lo. Uma boa relação entre o estudante e o professor é muito importante na sala de aula. (EN1).

Miguel: [...] Eu acho que uma atividade que o aluno sente prazer em fazer, ele faz. com mais dedicação. Sempre penso no que eu gostava de fazer quando era aluno do ensino médio. (EN1).

Em especial, Miguel retrata a época de estudante da Educação Básica, a qual ele toma como referencial para possíveis práticas futuras. Chamamos a atenção para este ponto, pois, conforme destaca Formosinho (2009), vivências passadas delimitam, de certa forma, a 
mobilização do PCK e, possivelmente, influenciam o PCK/NdC. Garcia (1999) reforça que professores em formação ou com pouca experiência docente, geralmente, se valem de práticas exitosas vivenciadas como estudante em suas futuras dinâmicas.

Sobre (e) a efetividade do texto histórico, Ana, Lucas, Paulo e Pedro destacam, com diferentes tonalidades, a potencialidade do texto histórico no ensino de conteúdos metacientíficos. Observem:

Ana: [...] A dificuldade está ligada com a prática de leitura dos alunos, pois a atividade necessita exclusivamente de leitura e interpretações. Nesse caso, os estudantes serão estimulados por ser uma atividade avaliativa. (CoRe). [...] Eu sinto dificuldade em trabalhar metodologias novas em sala de aula. Eu tenho medo da recepção dos alunos. Eu nunca trabalhei com texto. Se for uma tarefa que vale ponto, sintome mais confortável (ENF).

Lucas: [...] Já passou pela minha cabeça... Porque o seguinte, o grande problema desses alunos também é o analfabetismo funcional. Eles leem. Mas, no caso, eles não compreendem o que estão lendo. No caso, eu estava, passou pela minha cabeça, eu passar uns textos para eles lerem sobre este tipo de coisa, História da Física e Natureza da Ciência, como contexto da época que a Ciência nasceu ou como determinado conceito nasceu. Acho que seria bastante interessante. (EN1). [...] É um modo de incentivar a leitura e a interpretação de texto na disciplina de Física. Também uma forma de fazer com que os alunos adquirem um conhecimento melhor da Natureza da Ciência e da disciplina (CoRe).

Paulo: [...] Tentar propiciar um ambiente em sala de aula que favoreça a uma internalização dessas ideias por parte dos alunos. Incentivar a leitura de textos científicos é umas das estratégias utilizadas (CoRe).

Pedro: [...] A gente tenta implementar esses conteúdos na sala de aula. Mas, a gente é muito preso ao livro didático e o livro faz algumas vezes a citação de um autor e de forma errada. Não abre muito espaço e margem para discussão. Ele dá aquilo como verdade absoluta. Por exemplo, o caso da maçã de Newton. Como se ele tivesse estudado sozinho aquilo tudo. O livro didático, que é aprovado pelo MEC, não lhe oferece brechas para discutir a Natureza da Ciência na sala de aula, pelo menos de forma como eu imagino. Vai caber o professor se qualificar no assunto para poder trazer esse assunto. Eu imagino, agora, que a produção de um texto próprio é muito mais eficiente que os textos que os livros trazem. (EN1, grifo nosso).

Vale ressaltar alguns pontos nas falas dos participantes. Primeiro, Ana atrela a atividade, a qual envolve conteúdos metacientíficos, a certa pontuação para nota. Parece-nos que ela parece não se sentir confortável em aplicar novas metodologias de ensino, pois relaciona o sucesso das mesmas a uma possível boa recepção dos alunos, o que poderia ser feito com atividades avaliativas. Segundo, o destaque dado por Lucas para o analfabetismo funcional dos estudantes e a contribuição de textos históricos. Terceiro, Paulo retrata a potencialidade do texto histórico como fator de socialização entre os estudantes, propiciando a melhor circula- 
ção das ideias entre eles. Pedro tece uma crítica aos livros didáticos, no que diz respeito à qualidade dos textos históricos com potencialidade de ensino de conteúdos metacientíficos.

Ainda, conforme destaca Pedro, o uso de um texto próprio pode potencializar o ensino de conteúdos metacientíficos. Tal recurso é comumente utilizado em investigações de mestrado e doutorado (p. ex: SILVA, 2010; FORATO, 2009; MONTEIRO, 2014) que buscam levar discussões históricas e filosóficas da Física para a Educação Básica.

Sobre (e) os conceitos relacionados à NdC, Diego mostra que eles podem potencializar o uso de estratégias didáticas inovadoras em sala de aula. Contudo, também retrata a dificuldade relacionada à produção de atividades que envolvam conceitos de Física, História da Física e NdC entrelaçados.

Diego: [...] Eu vejo que a NdC me obriga a construir atividades que no dia-a-dia da sala de aula não uso. Nunca trabalhei com um texto, nem um científico. Sinto um desafio em abordar conteúdos da Física, sua história e NdC em texto. Acho complicado, mas acredito que isso mudará minha forma de enxergar a sala de aula, também. (ENF).

Sobre (f) o tempo das aulas, o pensamento dos nossos futuros professores de Física não difere do grupo de participantes da pesquisa de Martins (2007). Neste trabalho, a partir da fala dos seus investigados, o pesquisador retrata como grandes obstáculos à inserção de discussões de conteúdos históricos e filosóficos da Física, justamente, a falta de tempo para tal tarefa e o currículo engessado. Fenômeno similar é perceptível nas falas de Diego, Lúcia, Paulo e Pedro, como podemos notar:

Diego: [...] Bem... Com a experiência que estou tendo do estágio, eu ia sentir dificuldade para falar de Ciência, de método científico, o que é considerado Ciência e o que não é. Eles ainda têm muito da ideia da Ciência e do cientista como a gente tinha nas suas aulas, uma ideia de cientista como pessoa superior, uma pessoa que tem o intelecto fora do comum. Para eu mostrar para eles que não é assim, eu ia ter que perder um tempo de aula para discutir isso aí bem com eles, até porque estou trabalhando no ensino fundamental e eles têm a cabeça cheia de ideias, mas não tão organizadas ainda. (EN1, grifo nosso).

Lúcia: Para ensinar estes conteúdos novos, eu teria certa dificuldade. Ele acarreta um pouco de tempo. Teria que se fazer um planejamento pensado nesse tempo extra. (EN1).

Paulo:Eu me baseei muito nos textos usados na disciplina para produzir o meu. Claro, a aula não é muito longa. Então, eu tentei mesclar o máximo possível entre a parte histórica e social e também os conteúdos de Física em si. Mas, a questão do tempo para fazer isso, foi um fator complicador. Demorei mais que o normal para ensinar o mesmo conteúdo sem a parte da NdC. (ENF, grifo nosso).

Pedro: Olha... Nós temos uma limitação de tempo no ensino médio para ensinar sobre a NdC. Então, na medida do possível, sempre questionar o que está sendo dado. 
Por exemplo, no livro didático e tentando abordar metodologias atualizadas e diferentes. Mas, sempre tentando ter o maior rendimento da aula e do aprendizado do aluno. Os problemas habituais... Porque para dar aula, você se prepara, seja de qualquer conteúdo. Você tem que se preparar bem antes. Então, você carece de recursos e fontes. Mas, a única problemática seria realmente a questão do tempo. $O$ tempo de ministrar os conteúdos novos dentro daqueles 50minutos, tanto para abordar os conteúdos como os temas diferenciados, como a Evolução e História da Física. (EN1, grifo nosso).

Por fim, sobre (g) as atividades lúdicas, Ana retrata a potencialidade daNdC na construção de atividades lúdicas.

Ana: Eu vejo uma boa oportunidade de fazer júri simulado ou bingo da Física com o episódio histórico que peguei, o da Óptica. Acho que essas atividades podem agradar mais os estudantes, são mais dinâmicas. Assim, vão aprender mais sobre a NdC. (EN2).

Assim, compreendemos que atividades que busquem a problematização, desde a construção até aplicação desta ferramenta didática na formação inicial de futuros professores de Física, podem contribuir para a construção do conhecimento das estratégias instrucionais para o ensino de conteúdos metacientíficos e, por consequência, do PCK/NdC. Outro elemento que destacamos, que também pode contribuir neste sentido, é que os futuros professores de Física tenham a oportunidade de vivenciar essas estratégias didáticas já durante o seu processo de formação inicial, sendo acompanhados desde o seu processo de criação, aplicação, análise e reflexão de suas potencialidades.

No próximo tópico, discutiremos alguns fatores que influenciam na construção do conhecimento do currículo de Ciências para ensinar conteúdos metacientíficos.

\section{IV.3 A influência do Conhecimento do currículo de Ciências para ensinar conteúdos metacientíficos}

Entendemos que este componente envolve o conhecimento que os futuros professores necessitam possuir sobre as metas e objetivos de aprendizagens dos alunos em relação aos conteúdos metacientíficos que desejam lecionar. Ele engloba o conhecimento de programas, documentos e materiais que são relevantes para o ensino de conteúdos metacientíficos, dando suporte ao professor para o planejamento de estratégias didáticas. Sintetizamos os fatores que influenciam no desenvolvimento desse conhecimento no quadro 6. 
Quadro 6 - Conhecimento do currículo de Ciências para ensinar conteúdos metacientíficos.

\begin{tabular}{|c|c|c|c|c|c|c|c|c|c|}
\hline \multirow[t]{2}{*}{ Categoria } & \multicolumn{9}{|c|}{$\begin{array}{c}\text { Presente no participante } \\
\text { da pesquisa }\end{array}$} \\
\hline & Ana & Diego & José & Lucas & Lúcia & Miguel & Paulo & Pedro & Ricardo \\
\hline $\begin{array}{l}\text { Diferencia a } \\
\text { Física da Mate- } \\
\text { mática }\end{array}$ & & & $\mathrm{x}$ & $\mathrm{x}$ & & $\mathrm{x}$ & $\mathrm{x}$ & & \\
\hline $\begin{array}{l}\text { Influências de } \\
\text { contextos histó- } \\
\text { ricos, sociais e } \\
\text { religiosos na } \\
\text { Física }\end{array}$ & $\mathrm{x}$ & $\mathrm{x}$ & $\mathrm{x}$ & $\mathrm{x}$ & $\mathrm{x}$ & & $\mathrm{x}$ & $\mathrm{x}$ & \\
\hline $\begin{array}{l}\text { Motiva o ensino } \\
\text { de Física }\end{array}$ & $\mathrm{x}$ & $\mathrm{x}$ & $\mathrm{x}$ & $\mathrm{x}$ & & & & & \\
\hline $\begin{array}{l}\text { Apresenta os } \\
\text { objetivos da } \\
\text { Ciência }\end{array}$ & $\mathrm{x}$ & $\mathrm{x}$ & & & & & & & $\mathrm{x}$ \\
\hline $\begin{array}{l}\text { Desmistifica a } \\
\text { imagem do cien- } \\
\text { tista }\end{array}$ & $\mathrm{x}$ & $\mathrm{x}$ & & & $\mathrm{x}$ & & & $\mathrm{x}$ & \\
\hline $\begin{array}{l}\text { Formação plura- } \\
\text { lista do estudante }\end{array}$ & & & & & $\mathrm{x}$ & & & & \\
\hline $\begin{array}{l}\text { Valoriza o ensi- } \\
\text { no de Física }\end{array}$ & $\mathrm{x}$ & & & $\mathrm{x}$ & & & $\mathrm{x}$ & & \\
\hline
\end{tabular}

Fonte: Elaborado pelos autores.

Tomando como base o quadro, separamos os fatores em dois grupos, a saber:

Grupo 1 - Fatores relacionados aos aspectos da NdC: (a) influências de contextos históricos, sociais e religiosos na Física; (b) apresenta os objetivos da Ciência e (c) desmistifica a imagem do cientista.

Grupo 2 - Fatores relacionados ao ensino de Física: (a) diferencia a Física da Matemática; (b) motiva o ensino de Física; (c) valoriza o ensino de Física e (d) formação pluralista do estudante.

De forma geral, notamos que os grupos 1 e 2 apresentam relações bi-direcionais, ou seja, um influencia diretamente no outro. Por exemplo, compreender os fatores do grupo 1, relacionados aos aspectos da $\mathrm{NdC}$, pode proporcionar a produção de estratégias didáticas que favoreçam a diferenciação entre a Física e Matemática, conforme observado nas falas de José e Miguel.

José: Porque eu acho que o aluno deve tirar aquela coisa que a Física é uma matemática com outro nome. A Física é muito mais além que resolver um problema utilizando um cálculo. Ela utiliza interpretação de textos e teorias. Associando a história, de onde surgiu aquele conhecimento, você conhecendo de onde aquele conhecimento surgiu, o contexto econômico e político, isso abre várias portas para o aluno sobre aquela disciplina e aquele conteúdo. (EN1) 
Miguel: Eu acho bem importante. Isso é para mostrar para os alunos que a Física e não é só Matemática e, sim, tem contexto histórico e desenvolvimento. (EN1).

Ou, até mesmo, valorizar e motivar o ensino de Física, conforme ressaltam Ana e Diego.

Ana: Eu acho importante para eles valorizarem mais nossa área e gostarem mais da Ciência, e quem sabe, tornar-se um cientista ou professor da área. (EN1).

Diego: Saber que cientistas também erram pode motivar os alunos. Acho que a História da Física pode mostrar que o cientista é uma pessoa normal, que erra como todo mundo. Uma aula com essas características pode valorizar bastante as aulas de Física. (EN2).

Vale ressaltar, por exemplo, a fala de Lúcia, que enxerga uma formação mais pluralista dos estudantes na escola. Para ela, além da Física, os alunos estão em contato com disciplinas da área de humanas e estas podem contribuir para abordagens que valorizem conteúdos metacientíficos.

Lúcia: Meu aluno não estuda só Física na escola, ele estuda História, Geografia, Filosofia e se eu conseguir envolver tudo na minha aula ou conversar com os outros professores, quem sabe eu não consigo mostrar que a Física também tem relações com esses assuntos. Acho que seria legal. Mas, acho difícil conversar com outros professores de outras disciplinas na escola. (ENF).

Com base no que foi extraído, notamos que este componente do PCK/NdC, nos futuros professores de Física investigados, procura dar subsídios para a produção de estratégias didáticas que valorizem e motivem o ensino de Física, de forma geral, e o de conteúdos metacientíficos, com destaque para a discussão da imagem do cientista e da Ciência, de forma específica, conforme ressaltam Paulo e Pedro.

Paulo: Como a gente discutiu muito. A gente tem muitas ideias erradas de quem foi o primeiro, só ele fez aquilo, só Newton construiu isso, Einstein fez isso tudo só e, hoje, sei que não é verdade. A gente tem que mostrar para os nossos alunos que o conhecimento científico em Física, principalmente, é formado por uma composição de pensadores e de pesquisadores. (EN1).

Pedro: Eles têm tudo pronto e não fazem ideia para que serve um cientista. A ideia é muito pouco em relação a isso. Até eu, que sou estudante universitário, não tinha tanta ideia de como era a profundidade assim do conhecimento, a quantidade de anos que se deu até chegar o que a gente tem hoje. Então, é muito importante, sim, eles saberem em relação à NdC. (EN1). 
Assim, para construção mais adequada deste componente do PCK/NdC, acreditamos que, inicialmente, a concepção de aspectos da $\mathrm{NdC}$ de futuros professores de Física precisa ser trabalhada nas formações iniciais, pois pesquisas (veja, por exemplo: LEDERMAN, 1992, 2007; SANTOS; SILVA, 2013) já mostram que as concepções de Ciência e do cientista são, em alguns casos, de natureza empírica, indutivista e elitista, algo que, mesmo de forma implícita, pode ser repassado para as atividades produzidas por futuros professores.

Um próximo ponto seria a discussão de documentos, programas e materiais ${ }^{13}$ que se propõem a fazer tal tarefa. Notamos, na nossa investigação, que os participantes não citaram nenhum documento relativo ao ensino de Física, como, por exemplo, os Parâmetros Curriculares Nacionais ou até mesmo a Base Nacional Comum Curricular, que estava em discussão e com grande exposição nas mídias sociais e televisivas naquele momento. Assim, a partir destas vivências do campo de pesquisa, defendemos que o conhecimento do currículo de Ciências para ensinar conteúdos metacientíficos e, por consequência, o $\mathrm{PCK} / \mathrm{NdC}$ destes professores em formação apresentariam um ganho significativo se estes pontos fossem melhores discutidos nos seus cursos de formação.

No próximo tópico, iremos discutir como se constrói o conhecimento da avaliação de conteúdos metacientíficos.

\section{IV.4 A influência do Conhecimento da avaliação de conteúdos metacientíficos}

Trabalhos anteriores como o de Hanuscin, Lee e Akerson (2010) já chamavam a atenção para o fato de professores de Ciências apresentarem certa dificuldade em avaliar a aprendizagem de conteúdos metacientíficos nas suas estratégias didáticas. Na nossa investigação, em especial, este fator também foi notado, inclusive na própria dificuldade dos participantes em expressarem seus pensamentos sobre a avaliação de conteúdos metacientíficos, dificultando o nosso acesso aos indícios que nos levassem a compreender os fatores que contribuem (ou não) para a construção da avaliação de conteúdos metacientíficos.

Contudo, buscando uma compreensão mínima deste componente do PCK/NdC, investigamos, nos textos históricos produzidos e em relatos extraídos das microaulas, algumas evidências que nos dessem suporte para o entendimento de como este componente se constrói. Iniciaremos nossas análises com um olhar sobre a produção de critérios de avaliação apresentados nos textos históricos produzidos na pesquisa. Notamos que os participantes trazem à tona propostas de avaliações superficiais, destacadas, na maioria, pela participação dos alunos no texto e em provas subsequentes:

José: A avaliação será mediante a participação dos alunos e através da resolução da atividade após o texto. (ENF).

\footnotetext{
13 Destacamos que não foi objetivo da pesquisa oferecer estes conhecimentos que deveriam fazer parte da base de ensino dos participantes, pois os mesmos já tinham cursado disciplinas da área de Didática e Ensino de Física que tratam destas temáticas. Não podemos, aqui, afirmar que nos cursos anteriores eles discutiram ou não tais temas, pois não foi o foco da investigação.
} 
Lucas: $O$ texto inicial sobre a evolução histórica da eletricidade irá mostrar apenas uma história superficial desse ramo da Física. Ao término, será aplicado um teste com enfoque mais histórico sobre a Eletricidade. (ENF).

Paulo: O texto histórico servirá para alicerçar o debate feito em sala. A avaliação será feita pela participação dos alunos no debate. (ENF).

Ana: Após o texto histórico, com respeito à avaliação dos alunos, será feito, mediante a apresentação dos mesmos sobre o conteúdo estudado, um júri simulado com a participação de questões norteadoras.(ENF).

Este mesmo ponto foi ressaltado em Hanuscin, Lee e Akerson (2010), como já destacamos. As pesquisadoras sinalizam a importância de outro olhar para esta questão nos cursos de formação de professores e, principalmente, no processo de elaboração de atividades que visem à inserção de conteúdos metacientíficos na sala de aula, indo ao encontro dos nossos resultados. Essa mesma dificuldade foi encontrada no processo de avaliação das microaulas, como podemos observar nos excertos das falas dos participantes.

Ana: O processo de construção da aula foi eficiente; uma vez que foi necessária uma reflexão sobre do que seria abordado e qual seria a melhor maneira de trabalhar o tema e questões sobre a NdC e os conteúdos envolvidos. Mas, no momento de refletir sobre o processo avaliativo, o mesmo pareceu-me difícil de encaixar e de ser coerente com o que eu queria. (ENF).

Diego: A maior dificuldade foi na hora de elaborar uma metodologia de avaliação para os alunos, no que se refere aos conteúdos históricos e da NdC. (ENF).

Concordamos com Carvalho e Gil-Pérez (2006), principalmente no que diz respeito à existência de uma possível noção de senso comum, muito persistente nos professores de Ciências, em relação à avaliação, esta, geralmente, entendida como uma sequência de teoriaexercício-prova, na qual a prova reflete os exercícios. Os autores, ainda, abordam a necessidade de uma reflexão crítica destas ideias e comportamentos, caracterizando-se como uma necessária mudança didática neste aspecto do processo de ensino e aprendizagem. Sendo assim, fazendo uma comparação com o PCK, que é um conhecimento tácito e de difícil acesso, acreditamos que a avaliação, principalmente de conteúdos metacientíficos, também apresenta uma característica de difícil análise, o que denota, dos cursos de formação de professores, um olhar mais sensível e reflexivo para esta questão.

\section{Conclusões do estudo}

O estudo, aqui descrito, teve como objetivo investigar como os futuros professores de Física, estudantes de uma universidade brasileira pública e matriculados em uma disciplina de Evolução Histórica da Física, mobilizam o PCK/NdC, em situações de ensino e aprendizagem. De forma mais específica, buscamos responder às quatros questões formuladas no tópico 
III deste trabalho. Na procura dessas respostas, fomos orientados pela proposta de avaliação do PCK/NdC de Silva e Martins (2018b), sistematizada na Fig. 4.

Acreditamos que o estudo apresenta certa ressonância com diversas pesquisas que buscam a compreensão do PCK/NdC na formação de professores de Ciências, principalmente com experiência em sala de aula (ver, por exemplo: Baxter e Lederman (1999); Aydin e Boz (2013); Berry, Depaepe e Van Driel (2016)) e, de forma específica, com menor intensidade, na formação inicial de professores de Ciências (ver, por exemplo: Hanuscin, Lee e Akerson (2010)).

Os resultados obtidos concordam com achados de pesquisas anteriores, como, por exemplo, Hanuscin, Lee e Akerson (2010), as quais descrevem a dificuldade dos futuros professores de Ciências em avaliar as suas propostas de ensino de conteúdos metacientíficos. Vamos ao encontro das autoras quando apresentamos o quanto é complexo o acesso de indícios dos fatores que facilitam ou dificultam a construção do conhecimento da avaliação de conteúdos metacientíficos, devido ao fato de os pesquisados apresentarem certa dificuldade em elaborar propostas avaliativas para suas atividades.

Nesse ponto, parece-nos que a formação dos futuros professores de Física, em especial a investigada nesta pesquisa, não dá maiores suportes para a criação de propostas de avaliação de conteúdos metacientíficos. Nesse caso, acreditamos que outro olhar dos cursos de formação inicial para esta questão, como relatam Hanuscin, Lee e Akerson (2010), torna-se um interessante ponto de partida. Assim, alguns fatores foram mencionados pelos participantes, como, por exemplo, o ineditismo do conteúdo e a sua complexidade, principalmente em trabalhar de forma interdisciplinar conteúdos da Física, da sua história e de Epistemologia da Ciência, referentes à disciplina de Evolução Histórica da Física.

Continuando o olhar sobre os conhecimentos efetivos da proposta de modelo avaliativo para o PCK/NdC de Silva e Martins (2018b), notamos que os participantes apresentavam poucas relações entre estes conhecimentos, possivelmente contribuindo para uma mobilização pouco elaborada do PCK/NdC, fato que vai ao encontro das discussões apresentadas por Kind (2009).

Entretanto, encontramos alguns fatores que contribuem na construção destes conhecimentos, como, por exemplo, o interesse demonstrado pelo conhecimento prévio dos alunos sobre aspectos da $\mathrm{NdC}$, o qual pareceu-nos fundamental para o conhecimento da compreensão de Ciência dos estudantes da Educação Básica e das estratégias instrucionais para o ensino de conteúdos metacientíficos.

Ou seja, como notado na pesquisa, a produção de atividades que motivem o interesse dos estudantes da Educação Básica pode contribuir no acesso das suas concepções iniciais de Ciência e do cientista. Na investigação, pudemos notar alguns fatores que colaborariam nesse sentido, como, por exemplo, o uso de recursos visuais - imagens e vídeos -, atividades lúdicas e textos históricos produzidos por professores em formação. Assim, a possibilidade de fracasso ou não em tarefas dessa natureza reside na construção de conhecimentos relaciona- 
dos às estratégias instrucionais para o ensino de conteúdos metacientíficos, o que denota a intrínseca relação entre os conhecimentos efetivos do PCK/NdC, como destacado na Fig. 4.

$\mathrm{Na}$ construção do conhecimento relacionado ao currículo de Ciências para ensinar conteúdos metacientíficos, notamos que ele se fundamenta em dois grandes blocos (fatores relacionados à $\mathrm{NdC}$ e fatores relacionados ao ensino de Física). Na investigação, foi perceptível que eles se entrelaçam nas falas dos participantes. Ou seja, a inserção de temas sobre a Ciência pode tornar o ensino de Física mais atraente, pois pode trazer à tona aspectos, às vezes, renegados das aulas, como, por exemplo, a imagem do cientista e como a Ciência é desenvolvida, dando-lhe características que tornam o ensino de Física mais humanista e pluralista, possibilitando discussões com outras disciplinas da Educação Básica.

De certa forma, a complexidade e o ineditismo de abordagens relacionadas ao ensino e a aprendizagem de conteúdos metacientíficos na formação inicial dos professores investigados obstaculizou a produção de estratégias didáticas, pois a pouca compreensão da própria natureza do conhecimento científico causou receios nos participantes em produzir atividades de algo que eles pouco "dominavam" conceitualmente - e também metodologicamente.

Face ao exposto, notamos que compreender o que o aluno já sabe sobre os aspectos da NdC balizou a construção de algumas propostas de ensino de conteúdos metacientíficos, o que torna importante uma discussão mais aprofundada desta temática na formação inicial.

Assim, sobre o conhecimento de conteúdos metacientíficos, notamos que os participantes que melhor os desenvolveram, no decorrer do estudo, apresentaram uma melhor predisposição para a construção de atividades que buscavam o ensino de conteúdos metacientíficos, bem como mobilizaram de forma mais robusta seus próprios $\mathrm{PCK} / \mathrm{NdC}$, o que justifica ainda mais a sua importância na formação inicial.

No que diz respeito aos outros conhecimentos da base de ensino, mesmo não sendo o foco central da nossa pesquisa, observamos que vivências anteriores, inclusive ainda enquanto estudantes do ensino médio, ajudaram a moldar o conhecimento pedagógico geral dos participantes e, posteriormente, o PCK/NdC. Práticas que buscavam uma maior interação, colaboração e reflexão dos futuros professores e atividades de natureza coletiva e colaborativa potencializaram o processo de reflexão coletiva, importante ferramenta no desenvolvimento do PCK, de forma geral, e do PCK/NdC, de forma específica.

Sobre o conhecimento do contexto, seguimos a definição de Shulman (1987). Na nossa pesquisa não observamos o desenvolvimento em nossos participantes. Uma possível explicação, talvez, seja devido à pouca interação que o grupo tinha com o seu lócus de trabalho, fator relevante na formação docente, conforme destacou o pesquisador citado acima.

De forma especifica, notamos que conhecer a natureza do PCK, de forma geral, e, de forma específica, do PCK/NdC (fatores que contribuem no seu desenvolvimento) pode possibilitar a construção de atividades, na formação inicial de professores de Ciências/Física, com maior impacto no seu desenvolvimento. Por fim, conhecer as características e vivências destas práticas, também, colabora com a construção de currículos mais adequados para tal tarefa. 


\section{Referências}

ABD-EL-KHALICK, F; BELL, R. L.; LEDERMAN, N. G. The nature of science and instructional practice: Making the unnatural natural. Science education, v. 82, n. 4, p. 417-436, 1998.

ABELL, S. K. Twenty years later: does pedagogical content knowledge remain a useful idea? International Journal of ScienceEducation, v. 30, n. 10, p. 1405-1416, 2008.

ACEVEDO, J. A. D. Enfoques explícitos versus implícitos em La enseñanza de la natureza de la ciência. Revista Eureka sobre Euseñanza y Divulgación de lãs Ciencias, v. 6, n. 3, p. 355-386, 2009.

AYDIN, S; BOZ, Y. The nature of integration among PCK components: A case study of two experienced chemistry teachers. Chemistry Education Research and Practice, v. 14, n. 4, p. 615-624, 2013.

BARDIN, L. Análise de conteúdo. Lisboa: Edições 70, 2009.

BAXTER, J. A.; LEDERMAN, N. G. Assessment and measurement of pedagogical content knowledge. In: GESS-NWESOME, J.; LEDERMAN, N.G. (Eds). Examining pedagogical content knowledge: PCK and science education. Netherlands: Kluwer Academic Publisher, 1999. p. 147-161.

BERRY, A.; FRIEDRICHSEN, P.; LOUGHRAN, J. (Ed.). Re-examining pedagogical content knowledge in science education. Routledge, 2015.

BERRY, A.; DEPAEPE, F.; VAN DRIEL, J. Pedagogical Content Knowledge in Teacher Education. In: LOUGHRAN, J; HAMILTON, M. L (Eds.). International Handbook of Teacher Education. Springer, p. 347-386, 2016.

BOLÍVAR, A. Conocimiento didáctico del contenido y didácticas específicas. Profesorado. Revista de currículum y formación del profesorado, v. 9, n. 2, p. 1-39, 2005.

CARVALHO, A. M. P.; GIL-PÉREZ, D. Formação de professores de ciências: tendências e inovações. São Paulo: Cortez, 2006.

DEMIRDÖĞEN, B.; UZUNTIRYAKI-KONDAKÇI, E. Closing the gap between beliefs and practice: Change of pre-service chemistry teachers' orientations during a PCK-based NOS course. Chemistry Education Research and Practice, v. 17, n. 4, p. 818-841, 2016.

FERNANDEZ, C. Revisitando a base de conhecimentos e o conhecimento pedagógico do conteúdo (PCK) de professores de Ciências. Ensaio Pesquisa em Educação em Ciências, v. 17, n. 2, 2015.

FLICK, U. Desenho da pesquisa qualitativa. Porto Alegre: Editora Artmed, 2009. 
FORATO, T. C. M. A Natureza da Ciência como saber escolar: um estudo caso a partir da história da luz. 2009. Tese (Doutorado) - Faculdade de Educação, Universidade de São Paulo, São Paulo.

FORMOSINHO, J. Formação de Professores: Aprendizagem profissional e acção docente. Portugal: Porto Editora, 2009.

GARCIA, C. M. Como conocen los professores la matéria que ensenan: algumas contribuições de La investigacion sobre conocimiento didactico del contenido. In: CONGRESSO INTERNACIONAL DE DIDÁTICAS ESPECÍFICAS NA FORMAÇÃO DO PROFESSOR, Santiago de Compostela, 1992. p. 1-35.

GARRITZ, A.; MELLADO, V. El conocimiento didáctico del contenido y La afectividad. In: GARRITZ, A; LORENZO, G (Eds.). Conocimiento Didáctico del Contenido. Una perspectiva Iberoamericana, Saarbrücken, Alemania: Editorial Academia Española, 2014, p. 229264.

GESS-NEWSOME, Julie; LEDERMAN, Norman G. (Ed.). Examining pedagogical content knowledge: The construct and its implications for science education. Springer Science \& Business Media, 1999.

GIBBS, G. Análise de dados qualitativos. Porto Alegre: Editora Artmed, 2009.

HANUSCIN, D. L.; LEE, M. H.; AKERSON, V. L. Elementary teachers' pedagogical content knowledge for teaching the nature of science. Science Teacher Education, v. 95, n. 1, p. 145-167, 2010.

KIND, V. Pedagogical content knowledge in science education: perspectives and potential for progress. Studies in science education, v. 45, n. 2, p. 169-204, 2009.

LEDERMAN, N. G. Student's and teacher's conceptions of the nature of science: a review of the research. Journal of Research in Science Teaching, v. 29, n. 4, p. 331-359, 1992.

LEDERMAN, N. G. Nature of Science: past, present and future. In: Abell, S. K (Org); Lederman, N. G (Org). Handbook of research of Science Education. Mahwal: Lawrence Erlball Associates, p. 881-880, 2007.

LOUGHRAN, J; MULHALL, P; BERRY, A. In search of pedagogical content knowledge in science: Developing ways of articulating and documenting professional practice. Journal of research in science teaching, v. 41, n. 4, p. 370-391, 2004.

MAGNUSSON, S.; KRAJCIK, J.; BORKO, H. Nature, sources, and development of pedagogical content knowledge for science teaching. In: Examining pedagogical content knowledge. Springer Netherlands, 1999. p. 95-132.

MARCON, D. Conhecimento pedagógico do conteúdo: a integração dos conhecimentos do professor para viabilizar a aprendizagem dos alunos. Caxias do Sul: Educs, 2013. 
MARCONI, M.A. Fundamentos de metodologia científica. São Paulo: Atlas, 2003.

MARTINS, A. F. P. História e Filosofia da Ciência no ensino: Há muitas pedras nesse caminho.... Caderno Brasileiro de Ensino de Física, v. 24, n. 1, p. 112-131, 2007.

MARTINS, A. F. P. Natureza da Ciência no ensino de ciências: uma proposta baseada em "temas" e "questões". Caderno Brasileiro de Ensino de Física, v. 32, n. 3, p. 703-737, 2015.

McCOMAS, W. F.; OLSON, J. K. The nature of science in international science education standards documents. In: The nature of science in science education: rationales and strategies. Springer Netherlands, 2002. p. 41-52.

MONTEIRO, M. M. Inércia e Natureza da Ciência no Ensino de Física: uma sequência didática centrada no desenvolvimento histórico do conceito de inércia. 2014. Dissertação (Mestrado em Ensino de Ciências e Matemática) - Universidade Federal do Rio Grande do Norte.

MOREIRA, M. A. Metodologia de Pesquisa em Ensino. São Paulo: Livraria da Física, 2011.

SANTOS, G. D.; SILVA, B. V. C. Natureza da Ciência por alunos de Licenciatura em Física. Latin-American Journal of Physics Education, v. 7, p. 630-647, 2013.

SANTOS, M. L.; SILVA, B. V. C.; CARVALHO, H. R.; NASCIMENTO, L. A. A Natureza da Ciência no Ensino Fundamental: Por que não? Experiências em Ensino de Ciências, v. 1, p. 1-31, 2017.

SHULMAN, L. Those who understand: Knowledge growth in teaching. Educational Researcher, p. 4-14, 1986.

SHULMAN, L. Knowledge and teaching: Foundations of the new reform. Harvard Education Review, v. 57, n. 1, p. 1-23, 1987.

SHULMAN, L. PCK: Its genesis and exodus. In: BERRY, A; FRIEDRICHSEN, P; LOUGHRAN, J (Ed.). Re-examining pedagogical content knowledge in science education. Routledge, p. 3-13, 2015.

SILVA, B. V. C. Controvérsias sobre a natureza da luz: uma aplicação didática. 2010. Dissertação. (Mestrado em Ensino de Ciências e Matemática) - Universidade Federal do Rio Grande do Norte.

SILVA, B. V. C. O desenvolvimento do conhecimento pedagógico do conteúdo referente à temática Natureza da Ciência na formação inicial de professores de Física. 2018. Tese. (Doutorado em Ensino de Ciências e Matemática) - Universidade Federal do Rio Grande do Norte. 
SILVA, B. V. C.; MARTINS, A. F. P. (em avaliação). A reflexão colaborativa no desenvolvimento do conhecimento pedagógico do conteúdo referente à temática Natureza da Ciência de futuros professores de Física, 2018a.

SILVA, B. V. C.; MARTINS, A. F. P. Uma proposta para avaliação do desenvolvimento do conhecimento pedagógico do conteúdo de futuros professores de Física acerca da temática Natureza da Ciência. Caderno Brasileiro de Ensino de Física, v. 35, n. 2, p. 389-413, $2018 b$.

VERDUGO-PERONA, J. J.; SOLAZ-PORTOLES, J. J.; SANJOSE-LOPEZ, V. El conocimiento didáctico del contenido em ciencias: estado de la cuestión. Caderno de Pesquisa, v. 47, n. 164, p. 586-611, 2017.

\section{Anexo A}

\section{Questões do diário de reflexão e seus respectivos objetivos}

\begin{tabular}{|c|c|}
\hline Diário de Reflexão & Questões \\
\hline Diário de Reflexão 1 & $\begin{array}{l}\text { 1. Quais relações podemos fazer entre os } \\
\text { episódios históricos estudados e a proposta } \\
\text { de [Martins, 2015]? (Observação: Tome } \\
\text { como referências as tabelas 1 e } 2 \text { do artigo) } \\
\text { 2. Como podemos discutir conteúdos metaci- } \\
\text { entíficos valendo-se da proposta de [Martins, } \\
\text { 2015] e dos episódios de História da Ciência } \\
\text { estudados?Idealize uma proposta de inserção } \\
\text { na sala escolhendo pelo menos } 1 \text { episódio } \\
\text { histórico. } \\
\text { (a) O episódio histórico escolhido. } \\
\text { (b) Os temas que se relacionam com o episó- } \\
\text { dio histórico. } \\
\text { (c) O objetivo da atividade, a metodologia de } \\
\text { ensino e como pretende avaliar a aprendiza- } \\
\text { gem do seu aluno. }\end{array}$ \\
\hline Diário de Reflexão 2 & $\begin{array}{l}\text { 1. Quais dificuldades você teve para a elabo- } \\
\text { ração do seu plano de aula, atividades e mi- } \\
\text { croaula? } \\
\text { 2. O que você considerou (ou desconsiderou) } \\
\text { no processo de construção do seu plano de } \\
\text { aula atividades e microaula? Por quê? } \\
\text { 3. Como você avalia o processo de constru- } \\
\text { ção das atividades e no planejamento da } \\
\text { microaula? Houve momentos de tensões } \\
\text { (dificuldades)? Descreva-os. }\end{array}$ \\
\hline
\end{tabular}

Fonte: (Silva, 2018). 


\section{Anexo B}

\section{Questões das entrevistas}

\begin{tabular}{|c|c|c|c|}
\hline & Entrevista 1 & Entrevista 2 & Entrevista 3 \\
\hline Questões & 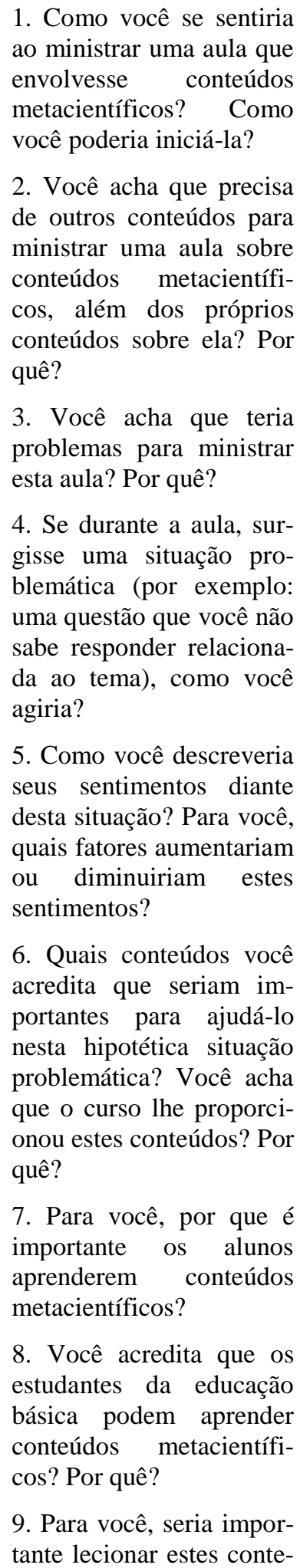 & 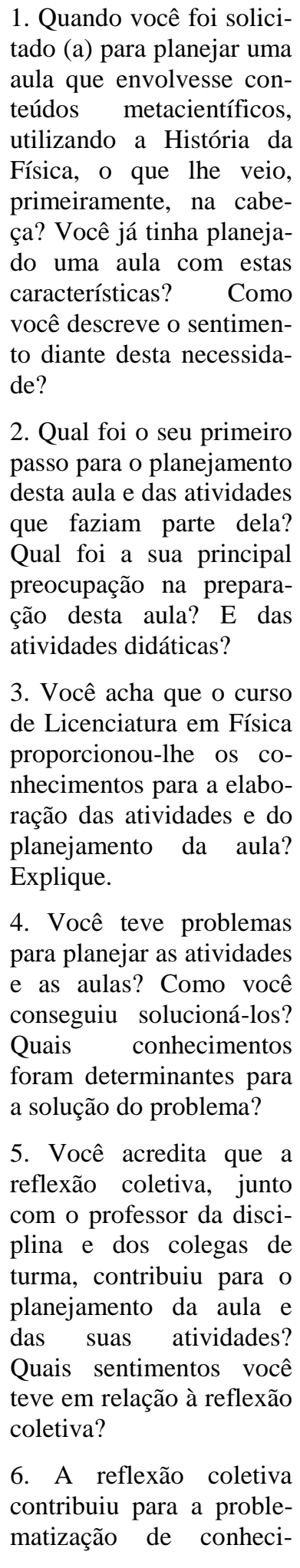 & $\begin{array}{l}\text { 1. No que você acha que a } \\
\text { escrita do diário reflexivo } \\
\text { colaborou para a sua re- } \\
\text { flexão sobre a construção, } \\
\text { aplicação e avaliação de } \\
\text { estratégias didáticas que } \\
\text { visam o ensino de conteú- } \\
\text { dos metacientíficos? } \\
\text { 2. Que tipos de dificulda- } \\
\text { des (conceituais, proce- } \\
\text { dimentais ou metodológi- } \\
\text { cas) você teve para a } \\
\text { construção e avaliação de } \\
\text { suas estratégias didáticas? } \\
\text { Explique. } \\
\text { 3. Que tipos de dificulda- } \\
\text { des (conceituais, proce- } \\
\text { dimentais ou metodológi- } \\
\text { cas) você teve para a } \\
\text { construção, aplicação e } \\
\text { avaliação de sua microau- } \\
\text { la? Explique. } \\
\text { 4. Como você descreveria } \\
\text { sua atuação na microaula? } \\
\text { Lembra-se de algum mo- } \\
\text { mento de dificuldade na } \\
\text { sobre o desenvolvimento } \\
\text { da sua atuação em sala de } \\
\text { aula? }\end{array}$ \\
\hline
\end{tabular}




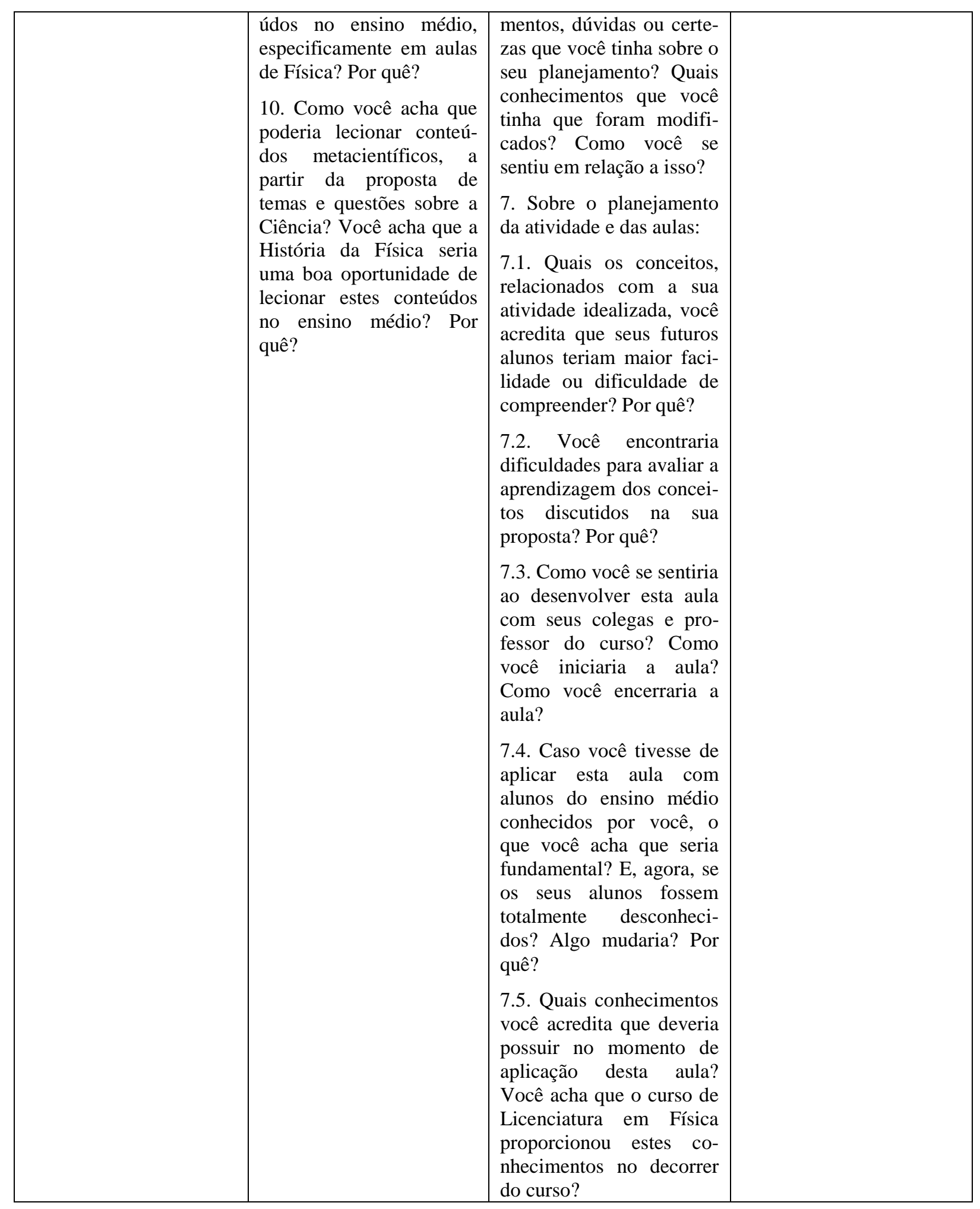

Fonte: (Silva, 2018). 